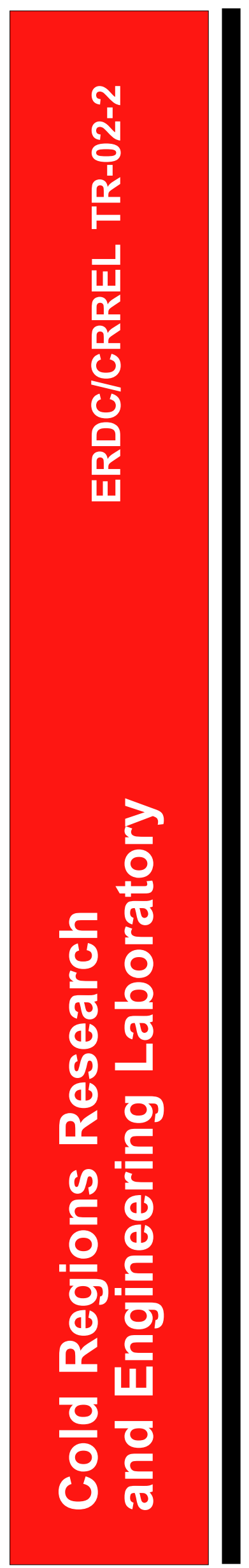

Maximum Impact Force of Woody Debris on Floodplain Structures

Robert B. Haehnel and Steven F. Daly

February 2002 
Abstract: We collided woody debris (i.e. logs) with structures using flume and test basin laboratory facilities to investigate the maximum impact force that floodplain structures are exposed to by floating woody debris. The tests investigated the influence of collision geometry and construction material of the structure face on the maximum impact forces. Collision geometry was determined by the debris orientation on impact. We reviewed the three approaches that represent the existing guidance on maximum impact forces. Each approach estimates the maximum impact force based on the debris velocity and mass. We show that all the existing approaches can be derived from a single-degree-of-freedom model of the collision and can be considered to be equivalent. The laboratory data show that the maximum impact force was associated with a log striking a rigid structure with its end. Oblique and eccentric collisions reduced the maximum impact load in a predictable and consistent manner. The approach we refer to as "contact stiffness," a linear, onedegree-of-freedom model with no damping, was able to reproduce the laboratory results over the entire range of data, with an effective contact stiffness of $2.4 \mathrm{MN} / \mathrm{m}$. All the existing guidance was applied to the laboratory data, and the strengths and weakness of each are discussed.

Support for this work was provided by

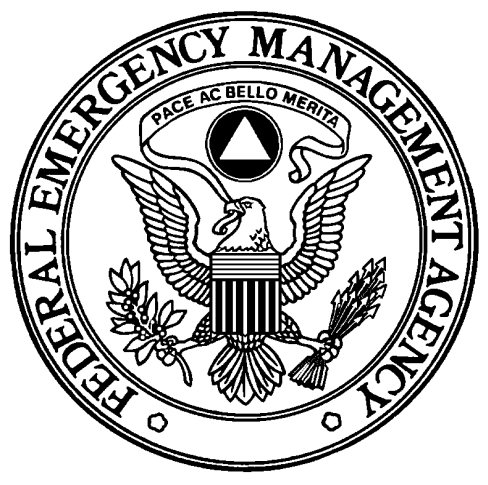

\section{\begin{tabular}{l}
1 \\
\hline
\end{tabular}}

How to get copies of ERDC technical publications:

Department of Defense personnel and contractors may order reports through the Defense Technical Information Center:

DTIC-BR SUITE 0944

8725 JOHN J KINGMAN RD

FT BELVOIR VA 22060-6218

Telephone (800) 225-3842

E-mail help@dtic.mil msorders@dtic.mil

WWW http://www.dtic.mil/

All others may order reports through the National Technical Information Service:

NTIS

5285 PORT ROYAL RD

SPRINGFIELD VA 22161

Telephone (703) 487-4650

(703) 487-4639 (TDD for the hearing-impaired)

E-mail_orders@ntis.fedworld.gov

WWW http://www.ntis.gov/index.html

For information on all aspects of the Engineer Research and Development Center, visit our World

Wide Web site:

http://www.erdc.usace.army.mil 


\section{Technical Report ERDC/CRREL TR-02-2}

\section{Maximum Impact Force of Woody Debris on Floodplain Structures}

Robert B. Haehnel and Steven F. Daly 


\section{PREFACE}

This report was prepared by Robert B. Haehnel, Research Mechanical Engineer in the Snow and Ice Branch, and Dr. Steven F. Daly, Research Hydraulic Engineer in the Remote Sensing/GIS and Water Resources Branch, U.S. Army Cold Regions Research and Engineering Laboratory (CRREL), Engineer Research and Development Center.

The Federal Emergency Management Agency funded this work. The authors thank Thomas McLane and Lorena Diaz of the American Society of Civil Engineers and Dr. David Kriebel of the U.S. Naval Academy for their support in executing this work. This work could not have been accomplished without the technical assistance of Michael Walsh, Dennis Lambert, Dr. Devinder Sodhi, John Gagnon, Gordon Gooch, and Charles Clark, all of CRREL.

This publication reflects the personal views of the authors and does not suggest or reflect the policy, practices, programs, or doctrine of the U.S. Army or Government of the United States. The contents of this report are not to be used for advertising or promotional purposes. Citation of brand names does not constitute an official endorsement or approval of the use of such commercial products. 


\section{EXECUTIVE SUMMARY}

We collided woody debris (i.e. logs) with structures using flume and test basin laboratory facilities to investigate the maximum impact force that floodplain structures are exposed to by floating woody debris. The tests investigated the influence of collision geometry and construction material of the structure face on the maximum impact forces. Collision geometry was determined by the debris orientation on impact.

We developed a one-degree-of-freedom model of a collision between woody debris and a rigid structure. A rigid structure is one whose stiffness is greater than the effective contact stiffness of the collision. The structure will also act as if it is rigid if the mass of the structure is so great that it doesn't move appreciably in response to the impact of the log. Lightweight structures without much mass and stiffness, relative to the log mass and effective contact stiffness, will not be adequately described by a one-degree-of-freedom model, so predicting forces on such structures is beyond the scope of this report.

We reviewed the three approaches that represent the existing guidance on design for impact loads: impulse-momentum (FEMA 1995), work-energy (NAASRA 1990), and contact stiffness (AASHTO 1998). Each of these approaches estimates the maximum impact force based on the debris velocity and mass. Each requires that an additional parameter be specified: impulsemomentum requires the stopping time; work-energy requires the stopping distance; and contact stiffness requires the effective contact stiffness of the collision. We show that all three approaches can be derived from a single-degree-offreedom model of the collision and are equivalent. We show that neither stopping time, in the case of impulse-momentum, nor stopping distance, in the case of work-energy, is an independent parameter. Stopping time depends on the effective contact stiffness and the debris mass; stopping distance depends on the effective contact stiffness, the debris mass, and the debris velocity.

The added mass of a floating log is zero for accelerations parallel to the long axis and at a maximum for accelerations perpendicular to the long axis. We present Matskevitch's analysis (1997) of the reduction in the maximum impact force caused by the eccentricity of impact. He demonstrated that the ratio of maximum impact forces for eccentric and non-eccentric impacts can be estimated based on a one-degree-of-freedom model using the geometrical properties of the impactor, its orientation on impact, and the coefficient of friction between the structure and impactor. 
All of the impact tests were conducted in the Cold Regions Research and Engineering Laboratory's Ice Engineering Facility. Tests using reduced-scale logs were conducted in the flume facility; tests using full-scale logs took place in the test basin. Eight test series were conducted. They investigated the maximum impact forces of reduced-scale logs in the flume; the qualitative probability of debris orientation on impact; the compatibility between the measurements of the maximum impact force in the flume and test basin; the maximum impact forces associated with full-scale logs in the test basin; the rigidity of the test structure; the effect of the material at the structure impact face on impact forces; and the effect of eccentricity and obliqueness of the debris impact on the maximum impact force.

The data that exhibited the most scatter were from the reduced-scale impact tests conducted in the flume. Flexure of the long logs used in the test basin reduced the measured maximum impact forces at $90^{\circ}$ impact orientations. The reduced-scale tests in the flume and the reduced-scale tests in the test basin produced similar and compatible results.

We systematically increased the stiffness of the structures used in the laboratory tests until the maximum impact forces were constant with further increases in stiffness. We determined that $2.4 \mathrm{MN} / \mathrm{m}$ is a good estimate of the effective contact stiffness between a log and a rigid structure.

We applied the existing guidance to our laboratory data. The effective contact stiffness is a constant for structures that can be considered rigid in collisions with logs. We demonstrated that stopping time and stopping distance are constants only over specified ranges of debris mass and velocity. As a result the contact-stiffness approach can be considered the most robust of the currently available guidance.

Laboratory tests demonstrated that the construction material of the impacted face of the rigid structure (wood, steel, or concrete) has no effect, in itself, on the maximum impact force.

The reduction in the maximum impact force due to the eccentricity is well described by Matskevitch's analysis (1997). Oblique collisions reduce the maximum impact load as the angle of impact (the included angle between the long axis of the $\log$ and the velocity vector of the log )is decreased from $90^{\circ}$.

The laboratory tests indicated that a log striking a rigid structure with its end (with the long axis of the log parallel to the flow direction and normal to the structure face, i.e. $0^{\circ}$ collisions) produced the maximum impact force. In this 
orientation, added mass is negligible, and the mass of the log can be used directly to compute the maximum impact force.

We qualitatively investigated the probability of the debris orientation on impact by conducting 200 tests in a laboratory flume with flowing water. In each test a $\log$ released upstream and in line with a pile-like structure floated freely with the current until impact. More than $40 \%$ of the released logs missed the structure altogether, the majority of the impacts were glancing blows, and fewer than $15 \%$ of the impacts produced a maximum load on the structure.

In an appendix we broadly discuss natural debris, which has trees as its source, and non-natural debris, which includes all man-made objects and debris that arises from the destruction and transport of structures in the floodplain. We briefly describe the genesis, evolution, and transport of natural woody debris. The large variability possible in the size and amount of woody debris reflects the large variability in the creation of woody debris and the episodic and random nature of the processes that recruit the woody debris to the stream channels and transport it away. 


\section{CONTENTS}

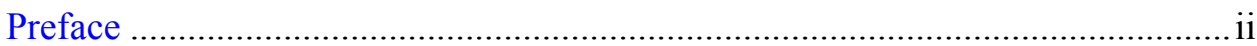

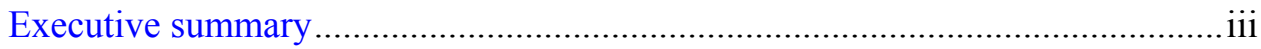

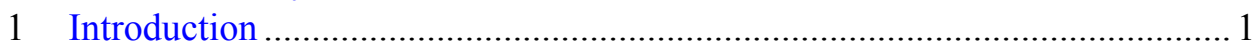

2 Estimating impact forces ............................................................................... 3

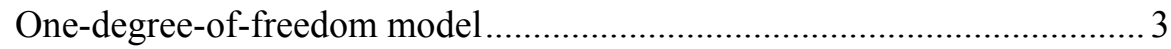

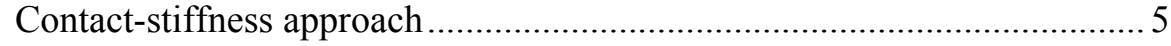

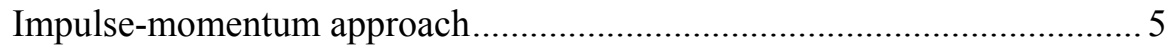

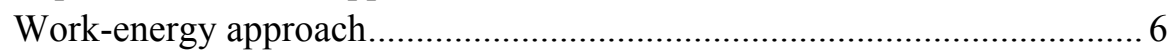

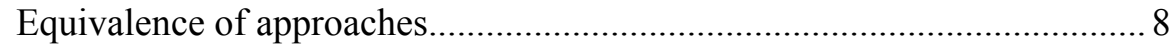

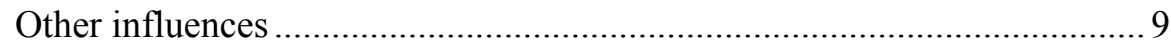

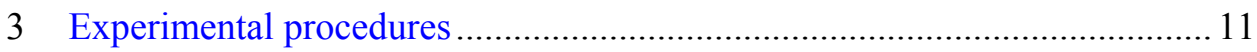

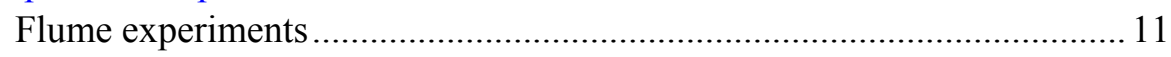

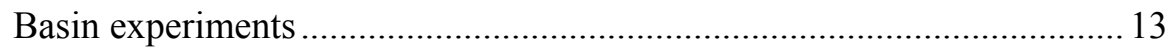

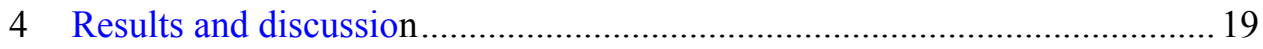

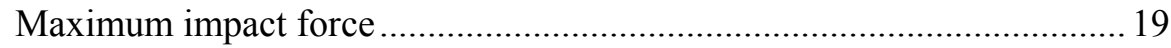

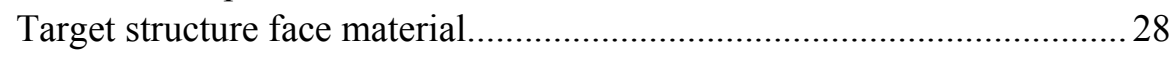

Debris orientation on impact................................................................... 29

Qualitative assessment of the probability of

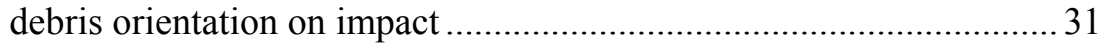

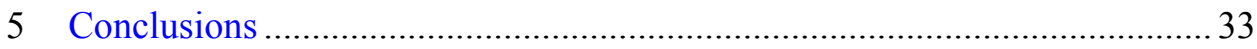

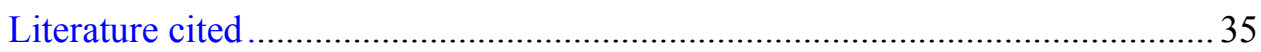

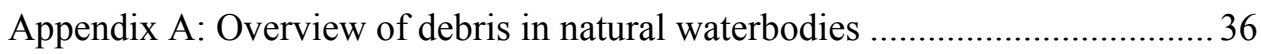

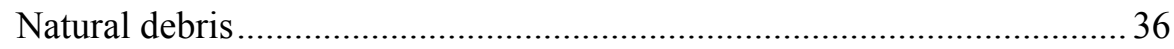

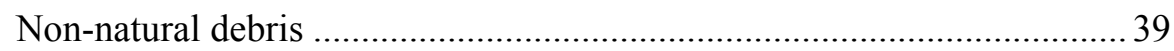

\section{LIST OF ILLUSTRATIONS}

Figure 1. Impact of a single debris element with a structure .............................. 3

Figure 2. Load frame used for measuring impact forces

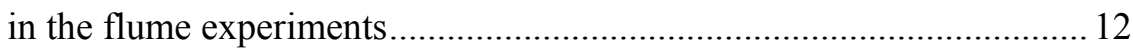

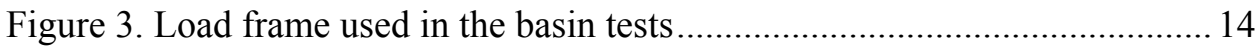

Figure 4. Setup for basin impact tests ............................................................. 18

Figure 6. Contact-stiffness approach applied to laboratory data .......................2 21

Figure 7. Predicted vs. measured values of impact force using the

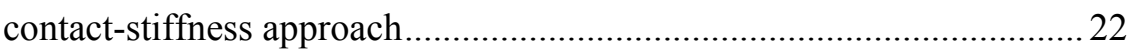

Figure 8. Impulse-momentum approach applied to the laboratory data ..............23

Figure 9. Predicted vs. measured values of maximum impact force using the impulse-momentum approach.............................................................. 24

Figure 10. Work-energy approach applied to laboratory data ............................ 25 
Figure 11. Predicted vs. measured values of impact force using the work-energy approach

Figure 12. Comparison of the three approaches for estimating the maximum impact force applied to a $455-\mathrm{kg} \log$ at various impact velocities.......... 27

Figure 13. Effects of target material on impact force ........................................ 28

Figure 14. Effects of eccentricity on impact force............................................. 29

Figure 15. Effects of orientation on impact force ….......................................... 30

Figure 16. Impact forces measured in the flume using a 5.9-kg $\log \ldots \ldots \ldots \ldots \ldots \ldots . . . . . . . .31$

Figure 17. Eccentricity of impact for samples that struck the target .................. 32

Figure 18. Impact orientation for samples that struck the target......................... 32

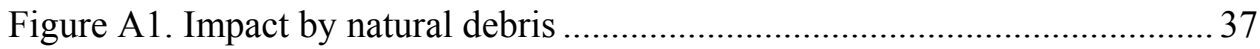

Figure A2. Impact by non-natural or man-made debris ....................................... 40

\section{LIST OF TABLES}

Table 1. Stopping distances of a 2-metric-ton (minimum) log impacting various bridge pier materials. 7

Table 2. Test matrix for the flume experiments ................................................... 13

Table 3. Test matrix for the basin-flume comparison experiments ..................... 15

Table 4. Test plan for the basin full-scale tests ................................................ 16 


\title{
Maximum Impact Force of Woody Debris on Floodplain Structures
}

\author{
ROBERT B. HAEHNEL AND STEVEN F. DALY
}

\section{INTRODUCTION}

Debris transported by floodwaters can strike residential, commercial, or other structures in the floodplain. These impacts reduce or redirect the velocity of the debris and impart a force to the structure. The magnitude of the force can be large enough to cause substantial, or even catastrophic, damage to the structures.

Flood-proofed structures must be designed to withstand the expected maximum impact loads. Estimating the maximum force on the structure is complex because the force is influenced by the properties of the debris, particularly its mass, velocity, and orientation on impact, and the properties of the structure itself, especially its stiffness and inertia.

At present there is no one accepted approach for estimating debris impact loads. There are, in fact, three distinct - although as we show, theoretically equivalent - approaches to estimating the maximum impact force. Each of these approaches estimates the maximum impact force based on the debris velocity and mass. All of the approaches are based on a one-degree-of-freedom system (i.e. only the mass of the debris is considered in the calculation of forces). The contact-stiffness approach is based on a one-degree-of-freedom spring-mass system where the stiffness of the interaction between the "debris" and the structure is assumed to be known. The American Association of State Highway Transportation Officials (AASHTO) LRFD Bridge Design Specifications (1998) uses this approach to estimate the loads resulting from ship collisions with bridge piers. The impulse-momentum approach equates the momentum of the debris and the time history of force, or impulse, imparted on the structure. In this approach the stopping time of the debris and the shape of the force function with time must be assumed. This approach is used in the flood-proofing guidance provided by the Federal Emergency Management Agency (FEMA 1995) and the U.S. Army Corps of Engineers (1995). The work-energy approach equates the energy of the debris with the work done on the structure. This approach requires an estimate of the distance the structure moves from the time of the initial contact of the debris 
until the debris comes to rest. The National Association of Australian State Road Authorities (NAASRA) Highway Bridge Design Specification (1990) guidance on designing bridges for debris impacts uses this approach.

The focus of this work was to obtain laboratory measurements of the forces caused by impacts of floating discrete woody objects (i.e. logs) on rigid structures. The tests investigated the influence of collision geometry and target material on the maximum impact forces. Collision geometry was determined by the debris orientation on impact. The target material is the construction material of the impacted face of the structure. These data were then used to evaluate the FEMA (1995), AASHTO (1998), and NAASRA (1990) guidance. In addition, limited tests were conducted to estimate the probabilities of collision and impact orientation between a pier-like structure and a log released in front of the structure a short distance upstream. Finally, impact loads can be considered to be the final step in a long chain of events, including the genesis, evolution, and transport of coarse woody debris in rivers and streams. We describe this briefly, but it is a separate area of study and has little direct bearing on the maximum impact force. 


\section{ESTIMATING IMPACT FORCES}

The guidance on impact forces can be classified according to the governing assumptions made to estimate the maximum forces. The three basic approaches are:

- Contact stiffness (AASHTO 1998)

- Impulse-momentum (FEMA 1995, U.S. Army Corps of Engineers1995)

- Work-energy (NAASRA 1990).

The aim of each approach is to estimate the maximum impact force based on the velocity and mass of the woody debris. Each requires an additional parameter: impulse-momentum requires the stopping time; work-energy, the stopping distance; and contact stiffness, the effective contact stiffness. In the following section we develop a one-degree-of-freedom model of the impact between woody debris and a structure. We review each of the above approaches and discuss the assumptions required by each for estimating the maximum force. We then discuss other influences that can affect the impact force: added mass and the debris orientation on impact.

\section{One-Degree-of-Freedom Model}

A log impacting a structure can be modeled as shown in Figure 1, where $m$ is mass, $k$ is stiffness (a linear constant of proportionality between penetration depth and force), $\zeta$ is damping coefficient, and $u$ is velocity. The structure has a stiffness, $k_{\mathrm{s}}$, associated with the supporting foundation and a mass, $m_{\mathrm{s}}$. The local

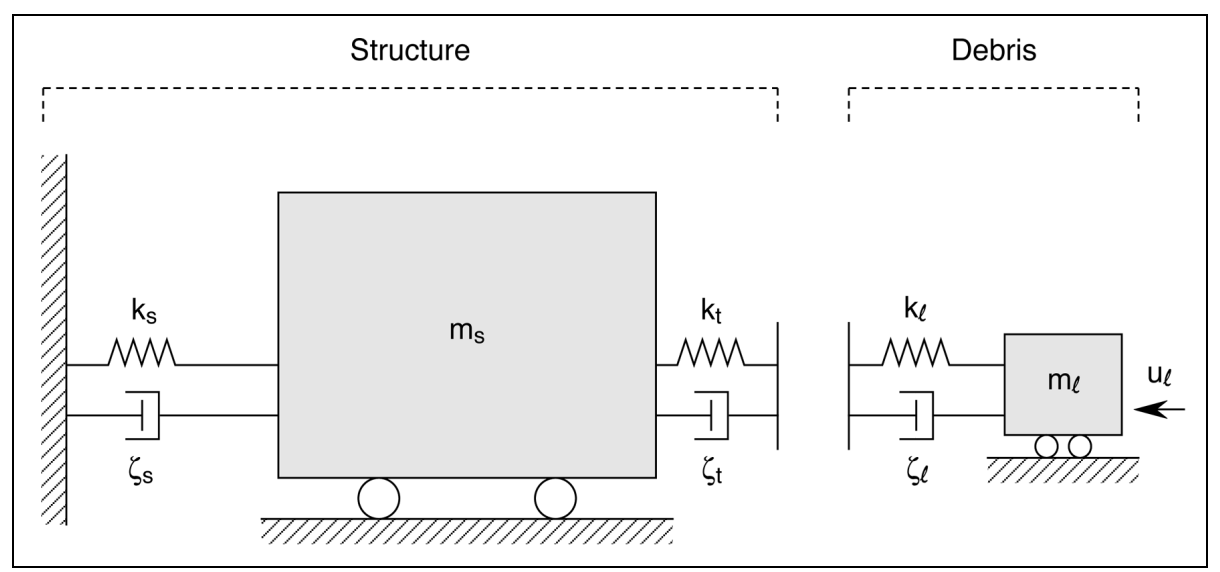

Figure 1. Impact of a single debris element with a structure. 
deformation of the structure at the impact zone is described with $k_{\mathrm{t}}$. The log has a mass of $m_{1}$ and an approach velocity of $u_{1}$. The elastic deformation of the log at impact is described by $k_{1}$. It is reasonable to assume that the collision occurs over such a short duration that damping can be neglected.

This system can be reduced to one degree of freedom if the structure can be considered to be rigid. The structure will be rigid if $k_{\mathrm{s}}>>\left(k_{\mathrm{t}}\right.$ and $\left.k_{1}\right)$, that is, the structure support stiffness is much greater than the stiffness of the target zone or the log. The structure will also act as if it is rigid if the mass of the structure is so great that it doesn't move appreciably in response to the impact of the log. The descriptive equation of such a one-degree-of-freedom model is

$$
m_{1} \ddot{x}+\hat{k x}=0
$$

where $\hat{k}$ is the effective contact stiffness of the collision

$$
\hat{k}^{-1}=\frac{1}{k_{\mathrm{t}}}+\frac{1}{k_{1}}
$$

The variable $x$ is the summation of the compression of the target face and the $\log$ during impact and rebound (e.g., $x=x_{1}+x_{\mathrm{t}}$ ), and the dot notation indicates the time derivative of $x$. At the moment of contact between the debris and the structure (i.e., $t=0$ ), $x=0$ and $\dot{x}=u_{1}$, so the solution of equation 1 is

$$
x=u \sqrt{\frac{m_{1}}{\hat{k}}} \sin \left(t \sqrt{\frac{\hat{k}}{m_{1}}}\right) .
$$

Given the linear relationship between the penetration depth and the normal force, $F=\hat{k x}$, the maximum impact force, $F_{\mathrm{i}, \max }$, predicted using eq 3 is

$$
F_{\mathrm{i}, \max }=u_{1} \sqrt{\hat{k} m_{1}} .
$$

Thus, the maximum impact force is a function of the impact velocity multiplied by the square root of the product of the effective contact stiffness and the debris mass. Note that the maximum impact force is independent of the properties of the structure if the structure is considered to be rigid. 
The analysis of a one-degree-of-freedom system given above is valid for debris impact provided that both the inertia and the stiffness of the structure are large enough that the structure itself does not move in any appreciable amount in response to the impact. This assumption results in the maximum impact forces for the relatively short impact durations we are investigating. However, a light structure that has soft foundation stiffness will move in response to the impact, and the system can only be accurately described by the two-degree-of-freedom equations of motion; in this case we expect the equations based on the onedegree-of-freedom analysis to overpredict the actual impact force.

\section{Contact-Stiffness Approach}

Equation 4 has the same form as the expression adopted for calculating vessel impact forces on bridge piers (AASHTO 1998), where the maximum collision force on the pier, $F_{\mathrm{v}}$, is based on the dead-weight tonnage of the vessel, $D W T$ (long tons), and the vessel velocity, $u(\mathrm{ft} / \mathrm{s})$. The adopted expression for the maximum impact force of a vessel collision, computed in English units and using an empirical coefficient for the stiffness, is

$$
F_{\mathrm{v}}(\mathrm{kips})=8.15 u \sqrt{D W T} .
$$

We refer to this approach for estimating the maximum impact force as the contact-stiffness approach because it requires only the effective contact stiffness of the collision to estimate the maximum impact force of an impactor with known mass and velocity.

\section{Impulse-Momentum Approach}

The impulse-momentum approach equates the impulse acting on the debris in contact with the structure with the change in momentum of the debris. The governing equation for this approach is based on the definition of impulse, $I$ :

$$
I=\int F(t) \mathrm{d} t=t_{\mathrm{i}} \bar{F}_{\mathrm{i}}=\int \mathrm{d}\left(u_{1} m_{1}\right)
$$

where $F$ is the force acting on the debris and is a function of time, $t, \bar{F}_{\mathrm{i}}$ is the time-averaged force, and $I$ is equal to the total change in the momentum of the debris over the course of the impact. Integration of eq 6 requires the functional relationship between impact force and time. If we use $\bar{F}_{\mathrm{i}}$ and assume that the momentum of the debris goes to zero as a result of the impact, then eq 6 becomes 


$$
\bar{F}_{\mathrm{i}}=\frac{u_{\mathrm{l}} m_{1}}{t_{\mathrm{i}}}=\frac{u_{1} w_{1}}{g t_{\mathrm{i}}}
$$

where $w$ is the weight $(=m g)$ of the debris, and $g$ is the gravitational constant. The impact duration, $t_{\mathrm{i}}$, is equal to the time between the initial contact of the debris with the structure and the maximum impact force. An independent estimate of $t_{\mathrm{i}}$ is required to estimate the impact force. The impulse-momentum approach has been adopted by FEMA (1995) and the U.S. Army Corps of Engineers (1995). [For brevity we refer to these works collectively as FEMA guidance since the FEMA publication, Engineering Principles and Practices for Retrofitting Flood-prone Residential Buildings (FEMA 1995), provides the most comprehensive description of applying the design approach.] Equation 7 is the expression used in the FEMA guidance. FEMA suggests that a value of $1 \mathrm{~s}$ be used for $t_{\mathrm{i}}$.

A limitation of eq 7 is that it gives the average impact force, not the maximum force, an important point that is not explicitly stated in the FEMA (1995) guidance. An expression for the maximum force, $F_{\mathrm{i}, \max }$, can be obtained if the function of the force with time, $F(t)$, is assumed. A linear rise of force with time would be the simplest approach. However, based on eq 3 we would expect that the functional dependence of force on time is sinusoidal, which results in

$$
F_{\mathrm{i}, \max }=\frac{\pi}{2} \frac{u_{1} m_{1}}{t_{\mathrm{i}}}
$$

\section{Work-Energy Approach}

In this case the impact force is computed by equating the work done on the structure with the kinetic energy of the debris element and assuming that the velocity of the debris goes to zero as a result of the collision:

$$
W=\int F(x) d x=\int d\left(\frac{1}{2} m u^{2}\right)
$$

where $W$ is the work done by the change in kinetic energy, $1 / 2 m u^{2}$. The force is a function of the distance, $x$, over which it acts $(F=k x)$. We define $S$, the stopping distance of the debris, as the distance the debris travels from the point of contact with the target until the debris is fully stopped $(u=0)$. Then eq 9 can be solved as follows: 


$$
\int_{0}^{s} k x d x=\frac{1}{2} m u_{0}^{2}
$$

or

$$
k S^{2}=m u_{\mathrm{o}}^{2} .
$$

Since $F_{\mathrm{i}, \max }=k S$, eq 11 becomes

$$
F_{\mathrm{i}, \max }=\frac{m u_{\mathrm{o}}^{2}}{S}=\frac{w u_{\mathrm{o}}^{2}}{g S} \quad \text { or } \quad F_{\mathrm{i}, \max }=\frac{2}{S} K E
$$

which is the expression used by NAASRA (1990) to compute impact forces of woody debris on bridge piers. To estimate the maximum design impact load, NAASRA recommends a range of stopping distances based on the bridge design for a $\log$ with a minimum mass of 2 metric tons $(4410 \mathrm{lbm})$ (Table 1). The stopping distances used in the NAASRA guidance vary with pier stiffness only, with shorter stopping distances for stiffer piers.

\begin{tabular}{|c|c|}
\hline $\begin{array}{l}\text { Table 1. Stopping distances of a 2-metric-ton } \\
\text { (minimum) log impacting various bridge pier } \\
\text { materials. (After NAASRA 1990.) }\end{array}$ \\
\hline Bridge pier material & $\begin{array}{c}\text { Stopping distance, S, } \\
\text { mm (in.) }\end{array}$ \\
\hline Timber & $300(11.8)$ \\
Hollow concrete & $150(5.9)$ \\
Solid concrete & $75(3.0)$ \\
\hline
\end{tabular}

Fenske et al. (1995) proposed a formulation nearly identical to eq 12 except that a coefficient, $C_{\mathrm{f}}$, is introduced to account for variations in the "stiffness of the bridge, relative angle of impact, fluid damping and [pier] mass:" 


$$
F_{\mathrm{i}, \max }=C_{\mathrm{f}} \frac{m u^{2}}{S}
$$

However, appropriate values of $C_{\mathrm{f}}$ and $S$ were not presented in that work.

\section{Equivalence of Approaches}

Though the above analyses of the maximum impact force are presented as three separate approaches, the one-degree-of-freedom model can be used to demonstrate that they are equivalent. We can use eq 3 to determine the values of $t_{\mathrm{i}}$ and $S$ that coincide with $F_{\mathrm{i}, \max }$. These are the values required by eq 8 and 12 :

$$
t_{\mathrm{i}}=\frac{\pi}{2} \sqrt{\frac{m_{1}}{\hat{k}}}
$$

and

$$
S=u_{1} \sqrt{\frac{m_{1}}{\hat{k}}}
$$

Substituting eq 14 into 8 or eq 15 into 12 yields

$$
F_{i, \max }=u_{1} \sqrt{\hat{k} m_{1}}
$$

which is identical to eq 4 .

Equations 14 and 15 show that impact duration and stopping distance are not constants that are independent of the properties of the logs involved in the collisions. Indeed, the impact duration depends on the mass of the debris and the contact stiffness of the interaction, while the stopping distance depends on the approach velocity as well as the debris mass and the contact stiffness. Treatment of $t_{\mathrm{i}}$ and $S$ as constants that are independent of debris mass and velocity has led to the disparate estimates of impact forces using these otherwise equivalent expressions. 


\section{Other Influences}

The analyses described above implicitly assume that the entire mass of the debris is uniformly affected by the collision, and they do not account for added mass or debris orientation. The entire mass of the log will not be uniformly affected in collisions that cause the log to rotate or merely redirect the trajectory of the log. Eccentric and oblique collisions tend to cause rotation of the entire $\log$. Collisions perpendicular to the long axis of "long" logs can cause the ends of the log to rotate as a result of flexure. We may expect the maximum impact force to be increased by added mass and decreased through oblique and eccentric collisions.

\section{Added Mass}

For an object accelerating in a fluid, the force required to accelerate the object is often greater than Newton's second law of motion $(F=m a)$ would predict. This difference in force is due to fluid drag and inertia and is often accounted for by computing the virtual mass (the mass of the object plus the added mass of the fluid) of the object that satisfies Newton's second law, or

$$
F=\left(m+C m_{\mathrm{f}}\right) a
$$

where $C$ is the added mass coefficient, and $m_{\mathrm{f}}$ is the mass of the fluid displaced by the object having mass $m$ and acceleration $a$. The value of $C$ depends on many variables, including the object's geometry, its degree of submergence, its orientation with respect to the direction of acceleration, and its natural vibration frequency. $C$ approaches zero for a long slender object (e.g. a log) with its axis oriented with the direction of acceleration (Sarpkaya and Isaacson 1981). However, $C=1$ for the same object accelerated normal to its axis.

Several log sizes and geometries were used in this study, including short rectangular timbers and long slender cylindrical logs. Estimates of the added mass coefficient for the geometries used in this study are given below. For small rectangular timbers with an impact angle of $0^{\circ}$, we assumed $C=0.22$; for fullsize cylindrical logs with the same impact orientation, we assumed $C=0$. For the $90^{\circ}$ impacts of the rectangular timbers, we assumed $C=2.4$ and 3.5 for square and rectangular timbers, respectively. For long cylindrical logs oriented $90^{\circ}$ to the flow, we used $C=1$. 


\section{Impact Eccentricity}

We cannot expect that logs impacting a structure will always have their long dimension parallel to the flow or that the axis of the collision will pass through the center of gravity of the log. The orientation of the log at impact can range from a square-on impact on the end of the log, through a range of oblique collisions as the $\log$ is rotated through $90^{\circ}$, to a broadside impact on the middle of the long length of the log. Eccentricity describes the degree to which the axis of the impact misses the center of gravity of the log. The reduction of the impact force as a result of eccentricity can be estimated using the analytic expression developed by Matskevitch (1997):

$$
\frac{F_{\mathrm{i}, \text { max }}}{F_{\mathrm{i}, \text { max }}^{90}}=\frac{1}{\sqrt{1+\left(\frac{\varepsilon_{\mathrm{o}}}{r_{\mathrm{i}}}\right)\left(1+\mu \frac{r_{\mathrm{o}}}{\varepsilon_{\mathrm{o}}}\right)}}
$$

where $\varepsilon_{0}$ is the distance from the center of gravity of the log to the point of impact, $r_{\mathrm{i}}$ is the radius of gyration for the $\log , \mu$ is the coefficient of friction between the target and $\log$, and $r_{\mathrm{o}}$ is the radius of the $\log . F_{\mathrm{i}, \max }^{90}$ is the impact force for a central impact with a $\log$ orientation of $90^{\circ}$. 


\section{EXPERIMENTAL PROCEDURES}

All of the tests were conducted in the Cold Regions Research and Engineering Laboratory's Ice Engineering Facility. Tests using reduced-scale logs were conducted in the flume facility; tests using full-scale logs took place in the test basin.

\section{Flume Experiments}

The flume allows tests that are hydrodynamically the same as conditions in the field, with the water and log moving and the target remaining stationary. The flume is capable of flows up to $0.25 \mathrm{~m}^{3} / \mathrm{s}$ (4000 gpm), and the bed slope can be varied to maintain a uniform flow depth. However, because the flume is small$1.22 \mathrm{~m}(4 \mathrm{ft})$ wide $\times 0.61 \mathrm{~m}(2 \mathrm{ft})$ high $\times 36.6 \mathrm{~m}(120 \mathrm{ft})$ long — only small (reduced-scale) logs could be used.

Logs of varying weight were used to measure the impact forces on a stationary load frame placed in the flow (Fig. 2). The load frame had a rounded target mounted on a front plate, which in turn was mounted on three load cells that were fastened to a rigid frame mounted on the flume floor. The rounded target kept the point of impact concentrated between the three load cells, assuring that all of the load cells were in compression on impact. Three 8900-N (2000-lbf) load cells were used. The loads were measured using a MegaDAQ digital data acquisition system. The sampling rate was $3 \mathrm{kHz}$, and a $1-\mathrm{kHz}$ anti-aliasing filter was used.

Two tests were performed in the flume, one to document factors affecting impact force (e.g. flow velocity, log mass, target material) and the other to look at the statistics of the impact force (e.g. impact frequency and orientation).

\section{Test Series 1}

In the first flume test series we varied log mass, flow velocity, impact orientation, and target material. Table 2 shows the levels for each of the factors studied in these experiments. The convention used for impact orientation was that $0^{\circ}$ indicated a $\log$ with its long axis parallel to the flow (head-on impact) and $90^{\circ}$ indicated a log aligned perpendicular to the flow (broad-side impact). The logs for the flume tests were cut from stock pressure-treated lumber (rectangular cross section).

The logs were released into the flow $7.6 \mathrm{~m}(25 \mathrm{ft})$ upstream of the load frame. This was a sufficient distance for the log to accelerate to the flow velocity before impact. Care was taken to ensure that the impacts were within a few 
degrees of the intended impact angle and that the logs struck the center of the target. If this was not the case, the test was repeated.

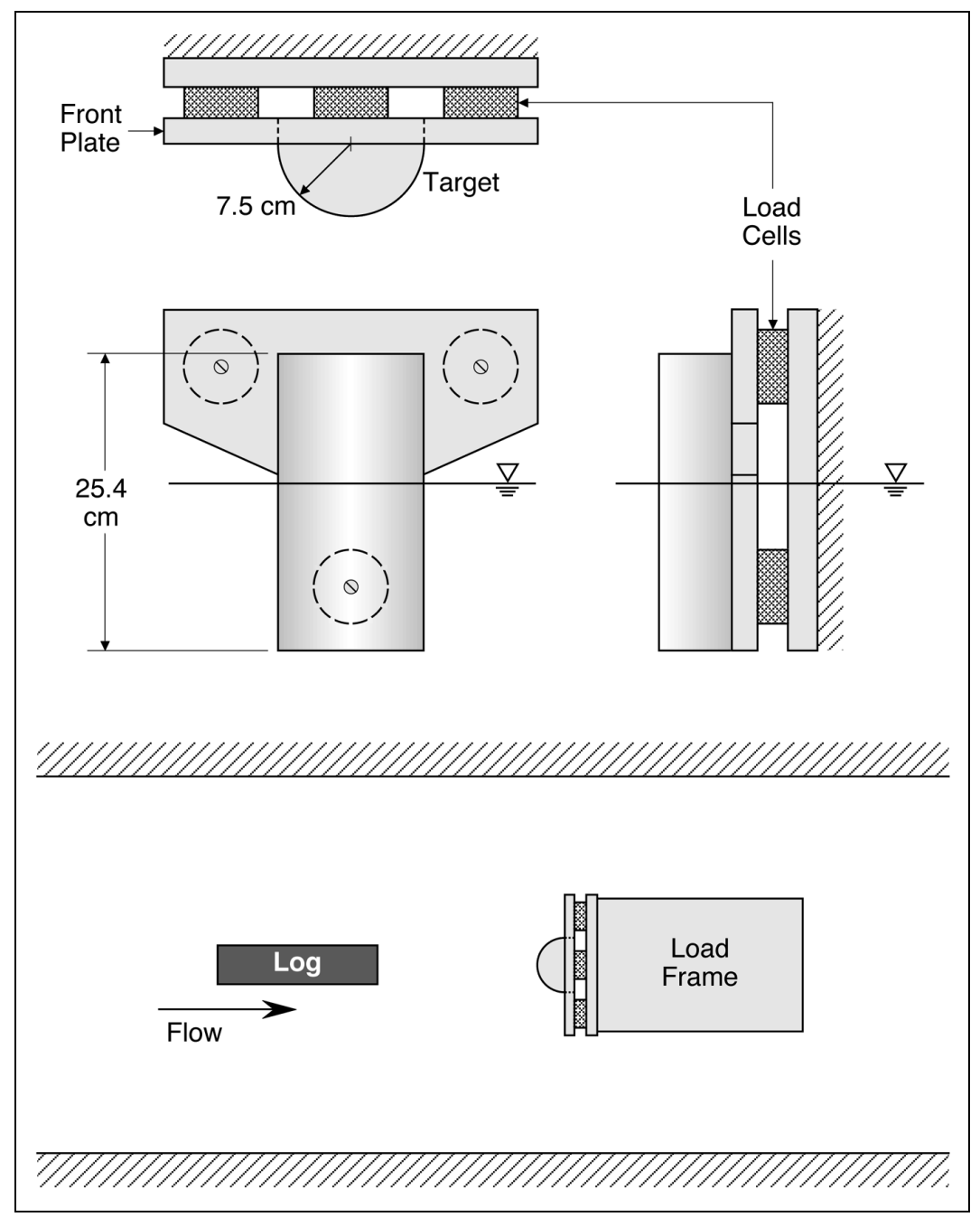

Figure 2. Load frame used for measuring impact forces in the flume experiments. 


\begin{tabular}{|c|c|c|c|c|}
\hline \multirow[b]{2}{*}{$\begin{array}{c}\text { Target } \\
\text { material }\end{array}$} & \multirow{2}{*}{$\begin{array}{c}\text { Impact } \\
\text { orientation } \\
\left({ }^{\circ}\right)\end{array}$} & \multicolumn{2}{|c|}{ Log } & \multirow{2}{*}{$\begin{array}{c}\text { Actual average } \\
\text { impact velocity, } \\
\mathrm{m} / \mathrm{s}(\mathrm{ft} / \mathrm{s})\end{array}$} \\
\hline & & $\begin{array}{c}\text { Actual mass, } \\
\text { kg (lbm) }\end{array}$ & $\begin{array}{l}\text { Dimensions, } \\
\text { cm (in.) }\end{array}$ & \\
\hline \multirow{5}{*}{$\begin{array}{l}\text { Wood } \\
\text { Steel }\end{array}$} & 0 & $5.90(13.0)$ & \multirow{2}{*}{$\begin{array}{c}8.9 \times 14 \times 91 \\
(3.5 \times 5.5 \times 36)\end{array}$} & $0.381(1.25)$ \\
\hline & \multirow[t]{4}{*}{90} & $12.0(26.5)$ & & $0.533(1.75)$ \\
\hline & & $14.4(31.8)$ & $\begin{array}{c}14 \times 14 \times 91 \\
(55 \times 55 \times 36)\end{array}$ & \\
\hline & & $19.7(43.5)$ & $\begin{array}{c}14 \times 19 \times 91 \\
(5.5 \times 7.5 \times 36)\end{array}$ & \\
\hline & & & $\begin{array}{c}19 \times 19 \times 91 \\
(7.5 \times 7.5 \times 36)\end{array}$ & \\
\hline
\end{tabular}

\section{Test Series 2}

A limited set of tests was performed in the flume to document the statistics of impact frequency and orientation. In these tests a flow velocity of $1.13 \mathrm{~m} / \mathrm{s}(3.69$ $\mathrm{ft} / \mathrm{s})$ was used. A 5.9-kg (13-lbm) log was placed in the flow $19 \mathrm{~m}(61 \mathrm{ft})$ upstream of the load frame. The log was placed generally in the center of the flow with an orientation of about $0^{\circ}$. The $\log$ was then allowed to flow freely until it reached the end of the flume. If the log impacted the target, the force was recorded. A video camera was mounted overhead to document the impact orientation. Though these tests were not a replicate model of any particular field condition, they allowed a qualitative investigation of the probability of the orientation of woody debris on impact.

\section{Basin Experiments}

The test basin is $9.1 \mathrm{~m}(30 \mathrm{ft})$ wide $\times 37 \mathrm{~m}(120 \mathrm{ft})$ long $\times 2.4 \mathrm{~m}(8 \mathrm{ft})$ deep and can easily accommodate logs that are prototype size. However, the water is stationary in the basin. For these tests we placed the log in the stationary water and mounted the target on the movable test carriage. This allowed us to ram the $\log$ with the target. The load frame used in the basin (Fig. 3) was similar to that used in the flume. The same rounded target and front plate were used in both the basin and flume. However, we mounted two 8.9-kN (2000-lbf) load cells on the top of the front plate and one 22-kN (5000-lbf) load cell on the bottom to allow measurement of the larger loads anticipated in the basin tests. The load cells 


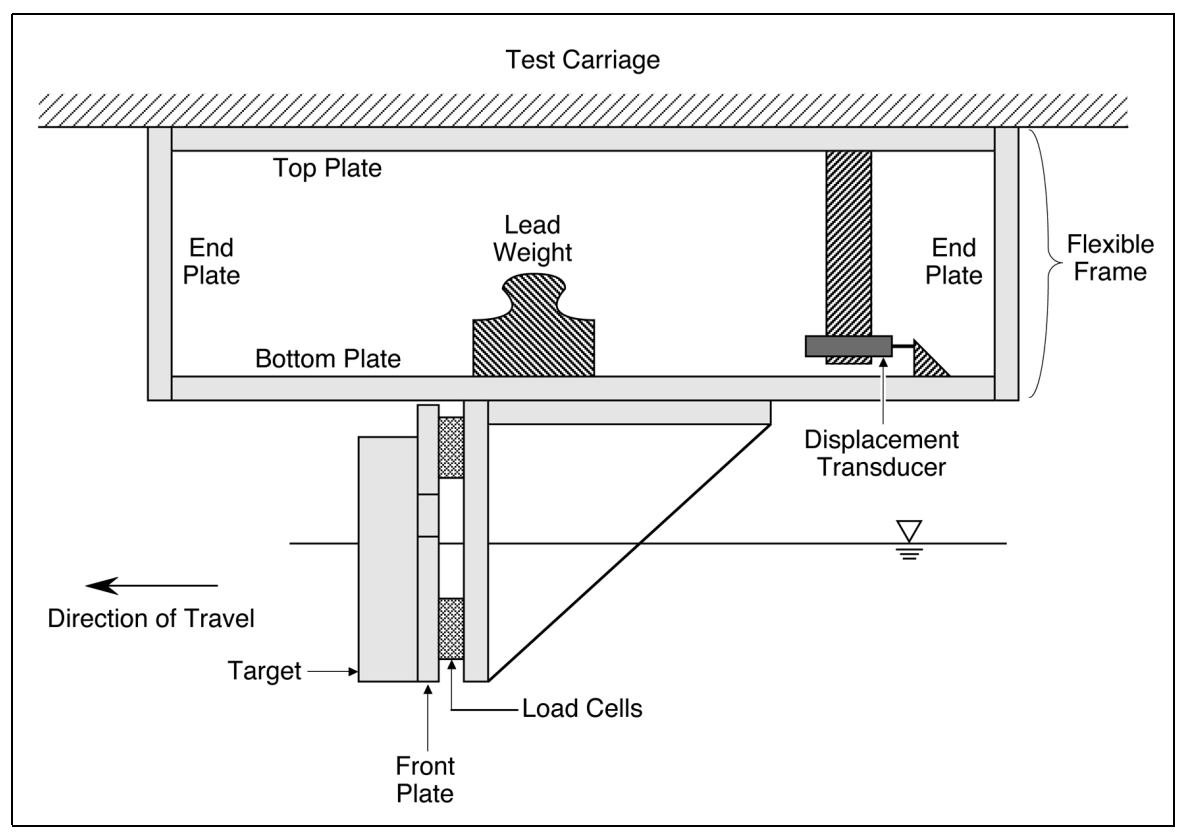

Figure 3. Load frame used in the basin tests.

were fastened to a flexible frame that was in turn mounted on the underside of the test carriage (Fig. 3). Substituting plates of varying thickness for the "end plates" varied the stiffness of the load frame. To make the frame extremely stiff, an additional longitudinal stiffener was added that extended between the two end plates.

\section{Test Series 3}

To confirm that the experiments in the flume and test basin would produce equivalent results, we ran a direct comparison with the flume tests by repeating the tests conducted with the $19.7-\mathrm{kg}(19-\times 19-\times 91-\mathrm{cm}) \log$ in the test basin. Table 3 shows the test matrix for these experiments. Three replicates at each level were performed.

\section{Test Series 4}

This test series used full-scale red pine logs in the test basin. Table 4 gives the test matrix for these experiments. These logs were $24-32 \mathrm{~cm}(9.5-12.5 \mathrm{in}$.) in diameter and 4.6-8.5 m (15-28 ft) long. The FEMA (1995) guidance gives a design $\log$ mass of $454 \mathrm{~kg}(1000 \mathrm{lbm})$. We could not accommodate a log this large in the test basin; the maximum log mass used in these tests was $330 \mathrm{~kg}$ (728 $\mathrm{lbm})$. The weight of the logs varied with the time they spent in the water. 


\begin{tabular}{|c|c|c|}
\hline \multicolumn{2}{|c|}{$\begin{array}{c}\text { Table 3. Test } \\
\text { comparison experiments (Test Series 3). }\end{array}$} \\
\hline $\begin{array}{c}\text { Impact velocity, } \\
\mathbf{m} / \mathbf{s} \text { (ft/s) }\end{array}$ & $\begin{array}{c}\text { Target } \\
\text { material }\end{array}$ & $\begin{array}{c}\text { Impact } \\
\text { orientation }\left(^{\circ}\right)\end{array}$ \\
\hline $0.381(1.25)$ & Steel & 0 \\
$0.800(2.62)$ & Steel & 0 \\
$0.381(1.25)$ & Wood & 0 \\
$0.800(2.62)$ & Wood & 0 \\
$0.381(1.25)$ & Steel & 90 \\
$0.800(2.62)$ & Steel & 90 \\
$0.381(1.25)$ & Wood & 90 \\
$0.800(2.62)$ & Wood & 90 \\
\hline
\end{tabular}

The logs were weighed at the beginning and end of each test day to determine the average weight for the associated tests. The range in weight of logs used was $171-330 \mathrm{~kg}(378-728 \mathrm{lbm})$. Tests were conducted at $0^{\circ}$ and $90^{\circ}$ orientations for a variety of impact velocities and two structural stiffnesses.

To control the impact orientation the logs were held in position with ropes that extended to the edges of the test basin. At the basin walls, 2.3- to 4.5-kg (5to $10-\mathrm{lbm}$ ) weights were placed on the rope to hold it in place until impact (Fig. 4, plan view). At impact the ropes pulled free, allowing the log to move freely in the water. One end of the log was rounded in the horizontal direction (Fig. 4, side view). Since the target was also rounded yet oriented in the vertical direction, the impact zone was essentially reduced to a point for $0^{\circ}$ impacts. Furthermore, since the logs were round, any impact other than $0^{\circ}$ was also at a point.

\section{Test Series 5}

Using various end plates and the longitudinal stiffener, we were able to vary the stiffness of the test structure in the test basin from 0.607 to $120.0 \mathrm{MN} / \mathrm{m}$, a factor of 200. Mounting lead weights on the bottom plate of the flexible frame varied the inertia of the frame. We could add up to $187 \mathrm{~kg}(413 \mathrm{lbm})$ to the frame, more than doubling the inertia of the load frame. We conducted tests on full-scale logs at $0^{\circ}$ orientation for a variety of impact velocities and a wide range of structural stiffness and structural inertia. Three replicates were conducted for each test. 
Table 4. Test plan for the basin full-scale tests.

\begin{tabular}{|c|c|c|c|c|}
\hline \multicolumn{5}{|c|}{$\begin{array}{l}\text { Series } 4: \text { Log mass, velocity and impact } \\
\text { Log Length }=8.53 \mathrm{~m}(28 \mathrm{ft}) \\
\text { Load frame weight }=127 \mathrm{~kg} \\
\text { Eccentricity }=0 \\
\text { Target = steel }\end{array}$} \\
\hline $\begin{array}{c}\text { Impact } \\
\text { orientation } \\
\left({ }^{\circ}\right)\end{array}$ & $\begin{array}{l}\text { Impact } \\
\text { velocity, } \\
\mathrm{m} / \mathrm{s} \text { (ft/s) }\end{array}$ & $\begin{array}{c}\text { Target frame } \\
\text { stiffness, } \\
\text { MN/m }\end{array}$ & $\begin{array}{l}\text { Log butt } \\
\text { diameter, } \\
\text { cm (in.) }\end{array}$ & Replicates \\
\hline \multirow[t]{19}{*}{0} & \multirow[t]{2}{*}{$0.076(0.25)$} & \multirow[t]{2}{*}{32.1} & $25(10)$ & 1 \\
\hline & & & $30(12)$ & 1 \\
\hline & \multirow[t]{2}{*}{$0.15(0.5)$} & & $25(10)$ & 1 \\
\hline & & & $30(12)$ & 1 \\
\hline & \multirow[t]{3}{*}{$0.30(1)$} & \multirow[t]{3}{*}{21.8} & $25(10)$ & 1 \\
\hline & & & $30(12)$ & 1 \\
\hline & & & & 1 \\
\hline & \multirow[t]{4}{*}{$0.61(2)$} & \multirow[t]{4}{*}{21.8} & $25(10)$ & 2 \\
\hline & & & $30(12)$ & 2 \\
\hline & & & $25(10)$ & 2 \\
\hline & & & $30(12)$ & 2 \\
\hline & \multirow[t]{2}{*}{$0.91(3)$} & \multirow[t]{2}{*}{21.8} & $25(10)$ & 2 \\
\hline & & & $30(12)$ & 2 \\
\hline & \multirow[t]{4}{*}{$1.2(4)$} & \multirow{4}{*}{32.1} & $25(10)$ & 2 \\
\hline & & & $30(12)$ & 2 \\
\hline & & & $25(10)$ & 2 \\
\hline & & & $30(12)$ & 2 \\
\hline & $1.5(5)$ & \multirow[t]{2}{*}{21.8} & & 1 \\
\hline & $1.8(6)$ & & & 1 \\
\hline \multirow[t]{8}{*}{90} & \multirow[t]{4}{*}{$0.61(2)$} & \multirow[t]{4}{*}{21.8} & $25(10)$ & 2 \\
\hline & & & $30(12)$ & 2 \\
\hline & & & $25(10)$ & 2 \\
\hline & & & $30(12)$ & 2 \\
\hline & \multirow[t]{4}{*}{$1.2(4)$} & \multirow[t]{2}{*}{21.8} & $25(10)$ & 2 \\
\hline & & & $30(12)$ & 2 \\
\hline & & \multirow[t]{2}{*}{32.1} & $25(10)$ & 2 \\
\hline & & & $30(12)$ & 2 \\
\hline
\end{tabular}


Table 4 (cont.). Test plan for the basin full-scale tests.

Series 5: Structure stiffness and inertia

Log dimensions $=8.53 \mathrm{~m} \times 25 \mathrm{~cm}$ butt diameter

Impact orientation $=0^{\circ}$

Target $=$ steel

Replicates $=3$

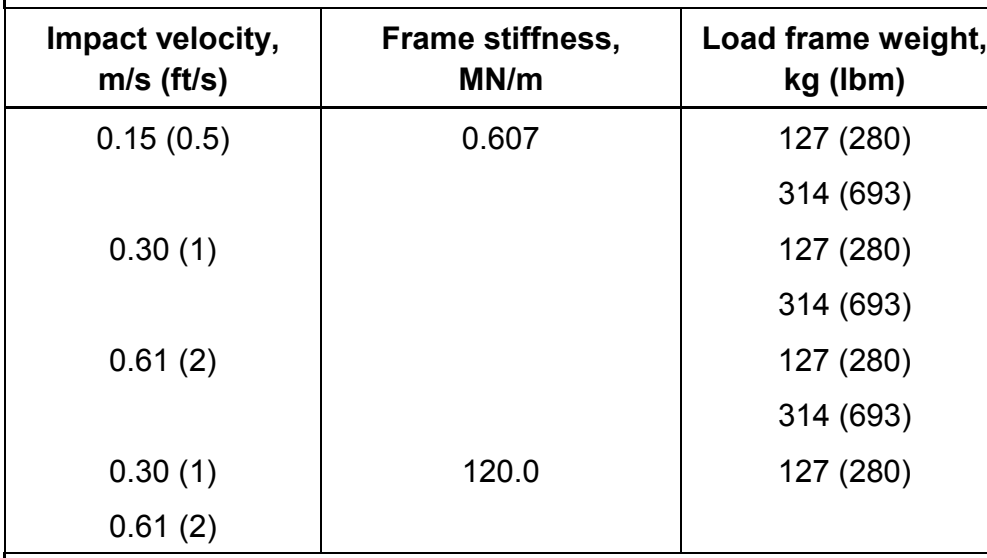

Series 6: Target material

Target $=$ wood or concrete

Log dimensions $=8.53 \mathrm{~m} \times 30 \mathrm{~cm}$ butt diameter

Impact orientation $=0^{\circ}$

Impact velocity $=1.2 \mathrm{~m} / \mathrm{s}(4 \mathrm{ft} / \mathrm{s})$

Frame stiffness $=120.0 \mathrm{MN} / \mathrm{m}$

Load frame weight $=127 \mathrm{~kg}$

Replicates $=3$

Series 7: Oblique impacts

Orientation $=0$ to $90^{\circ}$ in $10^{\circ}$ increments

Eccentricity $=0$

Log dimensions $=8.53 \mathrm{~m} \times 30.5 \mathrm{~cm}$ butt diameter

Impact velocity $=1.2 \mathrm{~m} / \mathrm{s}(4 \mathrm{ft} / \mathrm{s})$

Frame stiffness $=120.0 \mathrm{MN} / \mathrm{m}$

Load frame weight $=127 \mathrm{~kg}$

Target $=$ steel

Replicates $=3$

Series 8: Eccentric impacts

Impact location (distance from end of $\log$ ) $=0.305$ to $2.43 \mathrm{~m}$ ( 1 to

$8 \mathrm{ft}$ ) in $0.305-\mathrm{m}(1-\mathrm{ft})$ increments

Log dimensions $=4.88 \mathrm{~m}(16 \mathrm{ft}) \times 27.9 \mathrm{~cm}(11 \mathrm{in}$.$) butt diameter$

Impact orientation $=90^{\circ}$

Impact velocity $=1.2 \mathrm{~m} / \mathrm{s}(4 \mathrm{ft} / \mathrm{s})$

Frame stiffness $=120.0 \mathrm{MN} / \mathrm{m}$

Load frame weight $=127 \mathrm{~kg}$

Target $=$ steel

Replicates $=3$ 


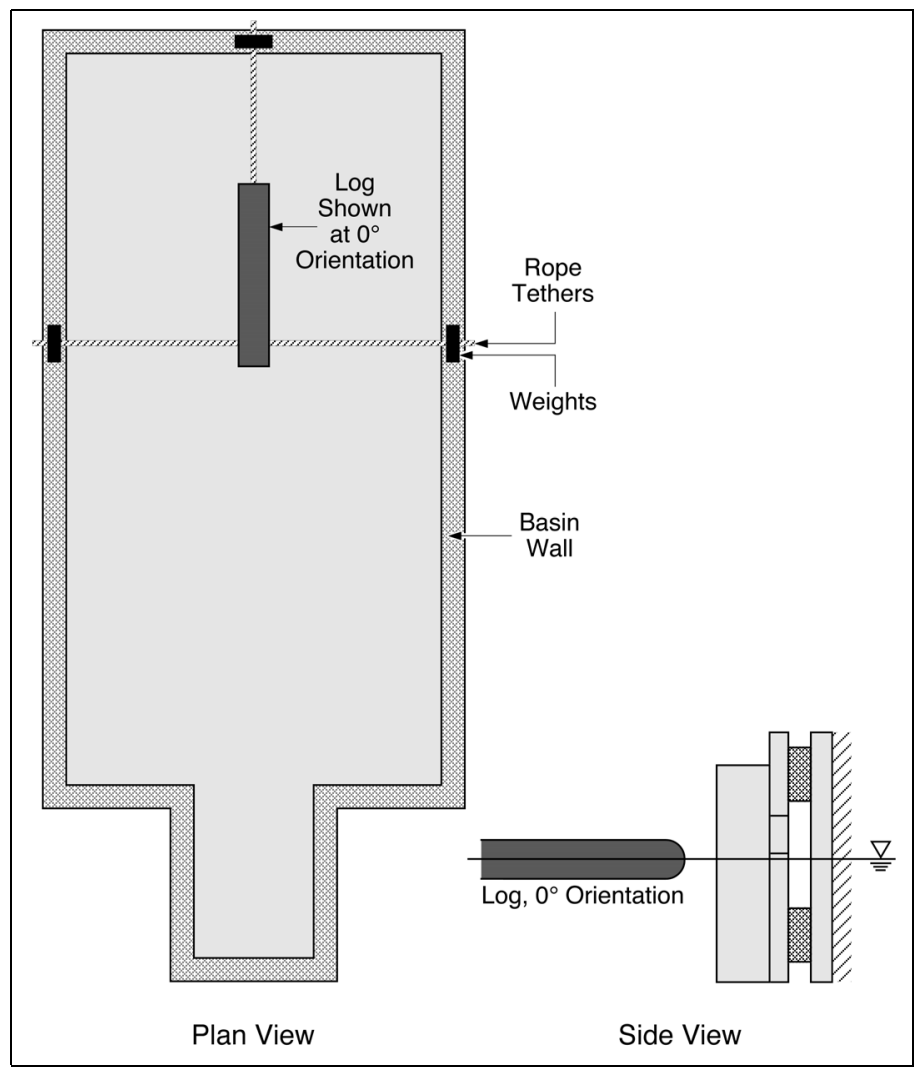

Figure 4. Setup for basin impact tests.

\section{Test Series 6}

To vary the target material type, the steel target was replaced with wood and concrete ones of the same size. To highlight the effect of the target material type, we conducted these tests using the stiffest test structure. The tests used full-scale $\operatorname{logs}$ at $0^{\circ}$ orientation and a single impact velocity. Three replicates were conducted for each test.

\section{Test Series 7 and 8}

In Test Series 7, Oblique Impacts, we varied the orientation of the debris impact from $0^{\circ}$ to $90^{\circ}$ in $10^{\circ}$ increments. The eccentricity was 0 for all these tests. In Test Series 8, Eccentric Impacts, we varied the eccentricity of the impacts by varying the impact location along the long axis of the log in $0.305-\mathrm{m}$ (1-ft) increments. All the impacts in Test Series 8 were carried out at an orientation of $90^{\circ}$. In both Test Series 7 and 8 a full-scale log was used, all tests were carried out at a single velocity of $1.2 \mathrm{~m} / \mathrm{s}(4 \mathrm{ft} / \mathrm{s})$, and we conducted these tests using the stiffest test structure. Three replicates were conducted for each test. 


\section{$4 \quad$ RESULTS AND DISCUSSION}

\section{Maximum Impact Force}

The relevant experimental results described above can be used to test the utility of the three approaches currently used for computing debris and vessel impact forces: contact stiffness (AASHTO 1998), impulse-momentum (FEMA 1995), and work-energy (NAASRA 1990). The data that we will use are those generated by Test Series 1,3 , and 4 . Tests were conducted at $0^{\circ}$ and $90^{\circ}$ orientations for a variety of impact velocities using reduced-scale logs in the flume and full-scale logs in the test basin. The complete time history of force was recorded for each test, along with the velocity and mass of the logs. The initial peak in the force record was selected as the maximum impact force. In the analysis below, the fluid added mass is included in computing the log mass.

Three observations of the data are in order at this point. First, the data that exhibit the most scatter are the reduced-scale impact tests conducted in the flume. Based on our observations during the tests, it is likely that the scatter in the flume data reflects the difficulty in controlling the exact impact geometry with an object moving with the flow. Slightly eccentric and oblique impacts were the rule rather than the exception in the flume tests, and the scatter in the data reflects the resulting reduction in forces. In Test Series 1 the exact orientation of the $\log$ at the time was not recorded, only the intended orientation of $0^{\circ}$ or $90^{\circ}$. Second, the full-scale tests in the test basin recorded in Test Series 4 at an orientation of $90^{\circ}$ and experiencing an impact at the midpoint of the log displayed a markedly lower maximum impact force than would be expected. The explanation for this reduction is undoubtedly flexure of the logs during impact. The large size of the logs allowed them to flex between their midpoint and their ends. The logs were therefore not accelerated uniformly along their length during an impact. And third, the reduced-scale tests in the flume and the reduced-scale tests in the test basin conducted in Test Series 3 produced similar and compatible results.

A short discussion is necessary at this point regarding the applicability of a one-degree-of-freedom model to the laboratory measurements. A one-degree-offreedom model is the basis of the three approaches currently used for computing debris and vessel impact forces. As stated earlier, it requires that the structure be rigid, that is, not move significantly during impact. This lack of movement can result either because the structure is much stiffer than the impacting debris or because the structure is massive and the debris rebounds off the surface of the structure before the structure moves appreciably. It is important that the laboratory data were collected under conditions that simulate a one-degree-of-freedom 
situation. The obvious means of assuring this was to ensure that the measured stiffness of the structure was much greater than the stiffness of a log. The actual stiffness of the laboratory structures was estimated through measurement of the natural frequency of the structures and through measurements of the structure displacement under static loads. Both estimates provided similar results. Surprisingly, however, it is not straightforward to estimate the stiffness of the wooden logs during the brief durations of impacts. The stiffness of the collision between the log and the structure is determined by the exact geometry of the impact zone of the log and the structure, the definition of which is beyond the scope of this study. An alternative means of assuring that the measurements are made under one-degree-of-freedom conditions is to successively increase the stiffness of the structure until the maximum impact forces reach a constant level that does not change with further increases in the structure stiffness. This process was conducted in Test Series 5, and the results are shown in Figure 5. It can be seen that the linear envelope containing the test results coincides with the data collected using a structure with a stiffness of $22 \mathrm{MN} / \mathrm{m}$ and that further increases in the structure stiffness to $120 \mathrm{MN} / \mathrm{m}$ did not increase the maximum impact forces. The linear envelope of the line containing the data provides an estimate

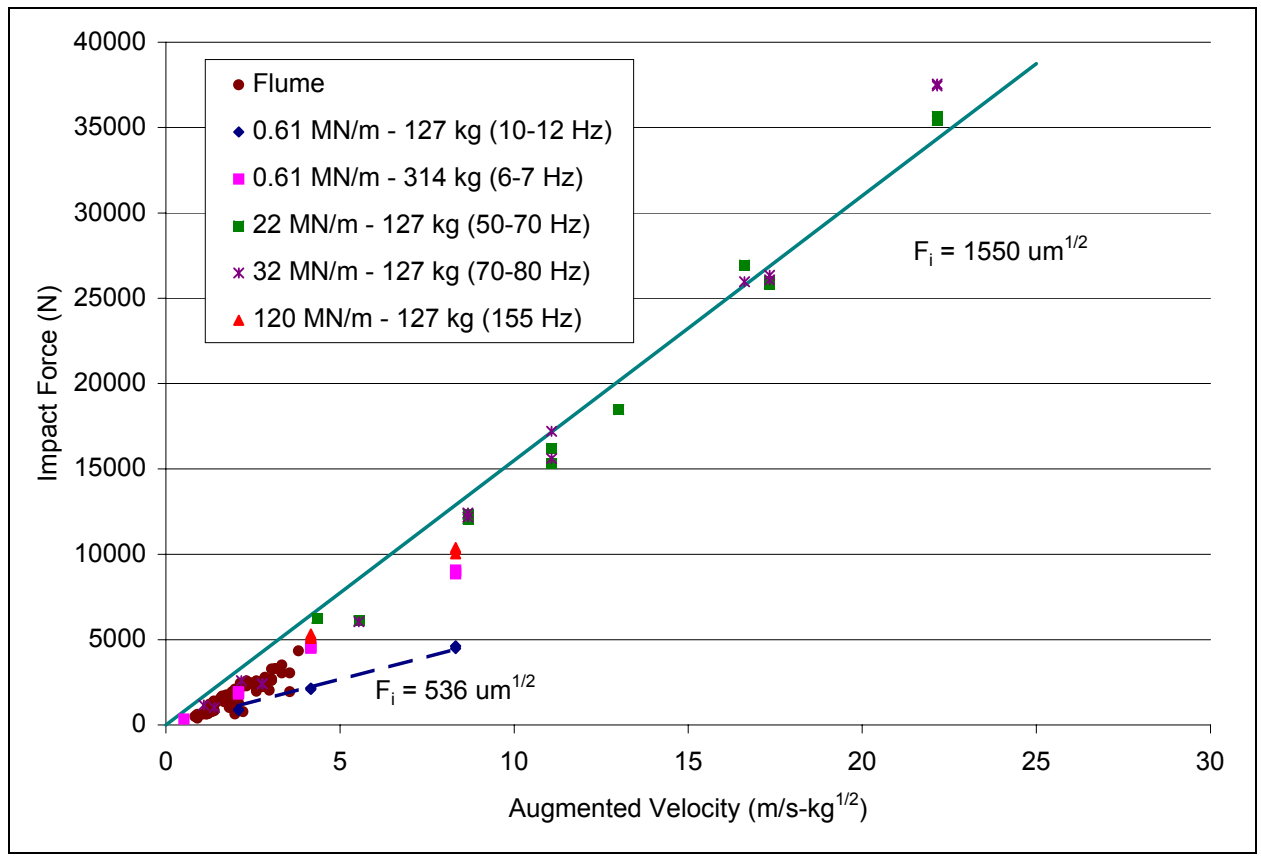

Figure 5. Effects of structure stiffness and mass on impact force (Test Series 1,4 , and 5 ). Only $0^{\circ}$ impacts are shown. 
of the effective contact stiffness of the collision of approximately $2.4 \mathrm{MN} / \mathrm{m}$, as will be discussed in the next section. This suggests that a structure can be considered to be rigid if the structure stiffness is at least 10 times the effective contact stiffness. All of our data (except for Test Series 5) were collected using structures with a stiffness of $22 \mathrm{MN} / \mathrm{m}$ or greater, indicating that a one-degree-offreedom model should be applicable.

\section{Contact-Stiffness Approach}

The measured maximum impact forces are plotted against the "augmented" velocity to evaluate the contact-stiffness approach (Fig. 6) using data from Test Series 1,3 , and 4 . The augmented velocity is $u \sqrt{m}$, where $u$ is the velocity of the $\log$ and $m$ includes the fluid added mass, if appropriate. It can be seen that a linear envelope would contain all the data. The slope of the line equals the square root of the effective contact stiffness, $\hat{k}$, which provides an estimate of $\hat{k}$ of approximately $2.4 \mathrm{MN} / \mathrm{m}$. The value of effective stiffness for collisions between woody debris and structures determined in this study is of the same order of magnitude as the effective stiffness $(14 \mathrm{MN} / \mathrm{m})$ used in eq 5 for predicting impact forces for vessels striking bridge piers. The maximum impact force for woody debris is, in newtons,

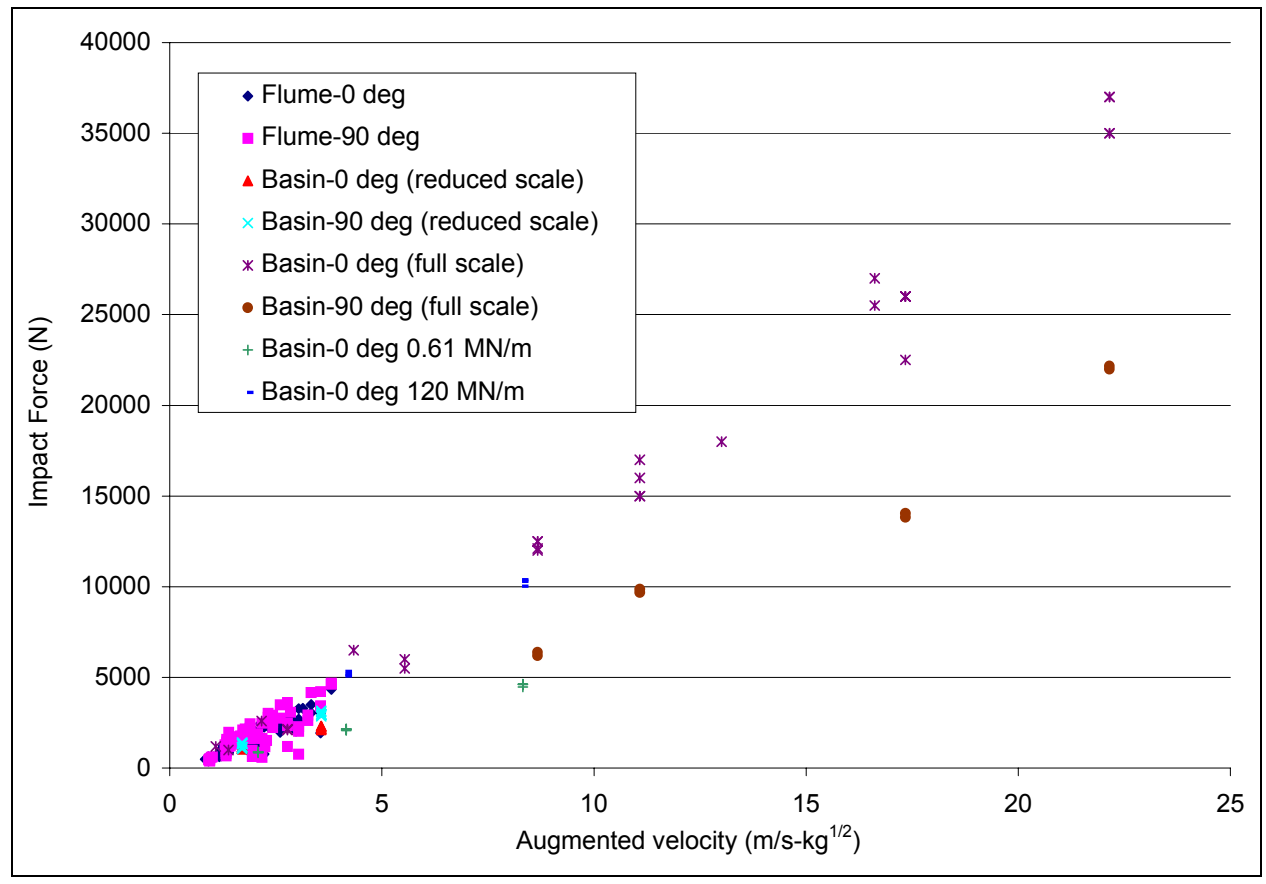

Figure 6. Contact-stiffness approach applied to laboratory data [Test Series 1 (flume), 3 and 4 (basin)]. Added mass is included for $90^{\circ}$ impacts. 


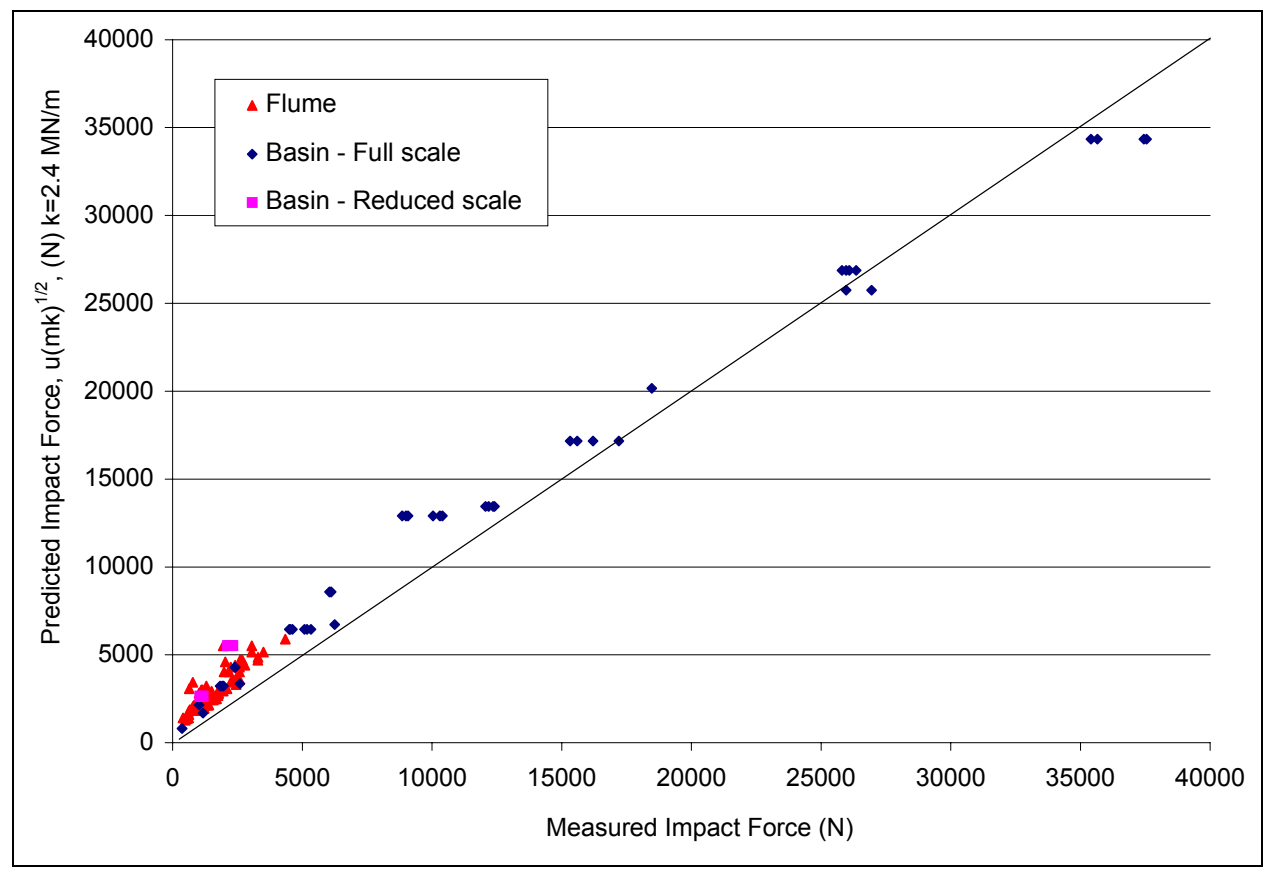

Figure 7. Predicted vs. measured values of impact force using the contact-stiffness approach (eq 18). The data are for $0^{\circ}$ impact orientation.

$$
F_{\mathrm{i}, \max }=1550 u \sqrt{m}
$$

where the velocity, $u$, is in $\mathrm{m} / \mathrm{s}$ and the mass, $m$, is in $\mathrm{kg}$. This approach (Fig. 7) tends to overpredict the impact forces for forces below $10 \mathrm{kN}$. This result was obtained using the effective stiffness value fitted to the upper limit of the measured impact forces. Equation 18 is equivalent to using eq 4 with $\hat{k}=2.4 \mathrm{MN} / \mathrm{m}$ and provides a slightly conservative prediction of the impact force over the full range of data measured in this study.

\section{Impulse-Momentum Approach}

The measured maximum impact forces are plotted against the debris momentum to evaluate the impulse-momentum approach (Fig. 8) using data from Test Series 1,3 , and 4 . The momentum is equal to $u m$, where $u$ is the velocity and $m$, the mass of the log; $m$ includes the fluid added mass, if appropriate. The impulse-momentum approach suggests that the average impact force should equal the product of the inverse of the stopping time, $1 / t_{i}$, and the debris momentum. The exact form of the relationship between the maximum impact force and momentum depends on the form of the impact force function with 


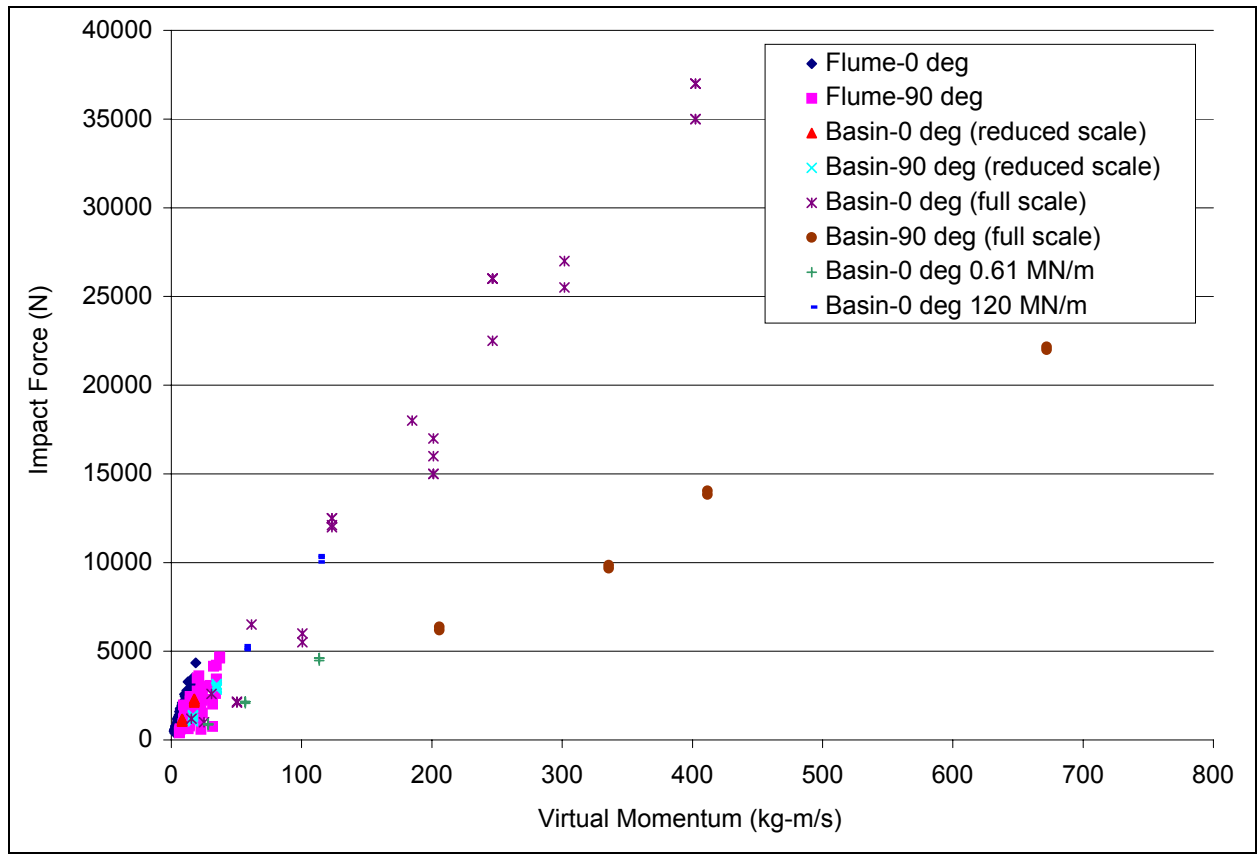

Figure 8. Impulse-momentum approach applied to the laboratory data [Test Series 1 (flume), 3 and 4 (basin)]. Added mass is included for $90^{\circ}$ impacts.

time. Our one-degree-of-freedom model provides a sinusoidal form and shows that the maximum impact force is equal to the product of the $\pi /\left(2 t_{\mathrm{i}}\right)$ and the debris momentum.

Let's examine the data for insights regarding appropriate stopping times. The measured stopping time (the time from the first contact of the log with the force measurement apparatus to the time the maximum impact force was measured) varied over a narrow range of time (about 6 to $24 \mathrm{~ms}$ ) for the range of velocities and log masses investigated. The average stopping time for the full-scale tests (i.e. $\log$ masses of $200-330 \mathrm{~kg}$ ) was $16.5 \mathrm{~ms}$. The slope of a line that passes through the upper bounding maximum impact force data shown in Figure 8 is $90.9 \mathrm{~s}^{-1}$. Using our one-degree-of-freedom model, we set $\pi / 2 t_{\mathrm{i}}=90.9 \mathrm{~s}^{-1}$, which provides a stopping time, $t_{\mathrm{i}}$, equal to $17 \mathrm{~ms}$. This agrees well with the average stopping time measured in the laboratory. Thus, the maximum impact force, based on the impulse-momentum approach, is, in newtons,

$$
F_{\mathrm{i}, \max }=90.9 u m
$$

where the velocity, $u$, is in $\mathrm{m} / \mathrm{s}$ and the mass, $m$, is in $\mathrm{kg}$. This equation is strictly applicable only for logs with masses in the range of $200-330 \mathrm{~kg}$. The ability of 


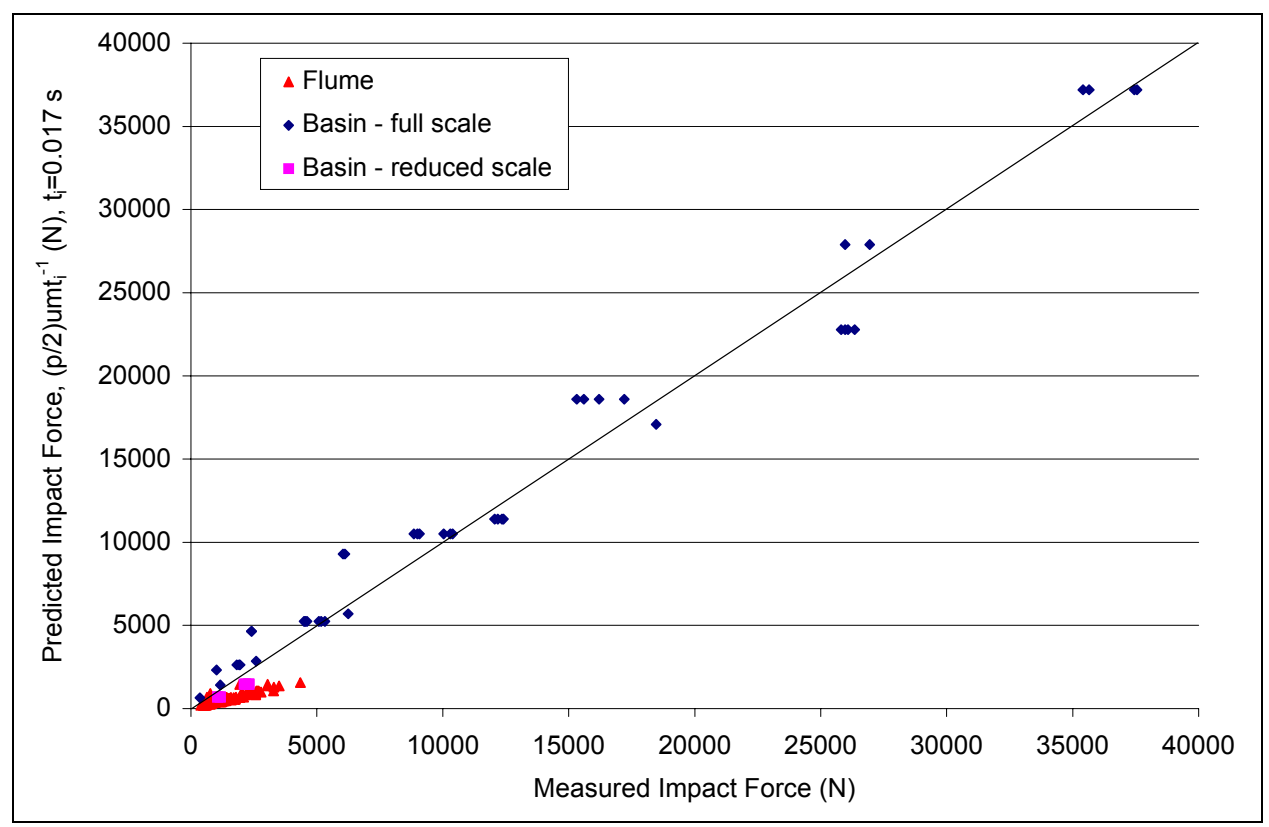

Figure 9. Predicted vs. measured values of maximum impact force using the impulse-momentum approach (eq 8). The data are for $0^{\circ}$ impact orientation.

this approach to predict the maximum impact forces can be seen in Figure 9. This approach consistently underpredicted the impact forces for the reduced-scale logs measured in the flume and test basin. This underprediction resulted from using a constant stopping time, rather than a stopping time that is a function of the debris mass, as indicated in eq 14.

\section{Work-Energy Approach}

The measured maximum impact forces are plotted against the debris kinetic energy to evaluate the work-energy approach (Fig. 10) using data from Test Series 1,3 , and 4 . The kinetic energy is equal to $1 / 2 m u^{2}$, where $u$ is the velocity and $m$, the mass of the log; $m$ includes the fluid added mass, if appropriate. The work-energy approach suggests that the maximum impact force should equal the product of the inverse of twice the stopping distance, $2 / S$, and the debris kinetic energy. Inspection of Figure 10 indicates that $S$ cannot be a constant, as the relationship between the maximum impact force and the debris kinetic energy is obviously not linear. This supports eq 15, which shows that $S$ is a function of the mass of the debris, the effective contact stiffness, and the velocity of the debris. We can develop an expression for $S$ by noting that the maximum impact forcekinetic energy relationship shown in Figure 10 is approximately linear for values of kinetic energy greater than $50 \mathrm{~J}(K E>50 \mathrm{~J})$ for $0^{\circ}$ impacts. For this range we 


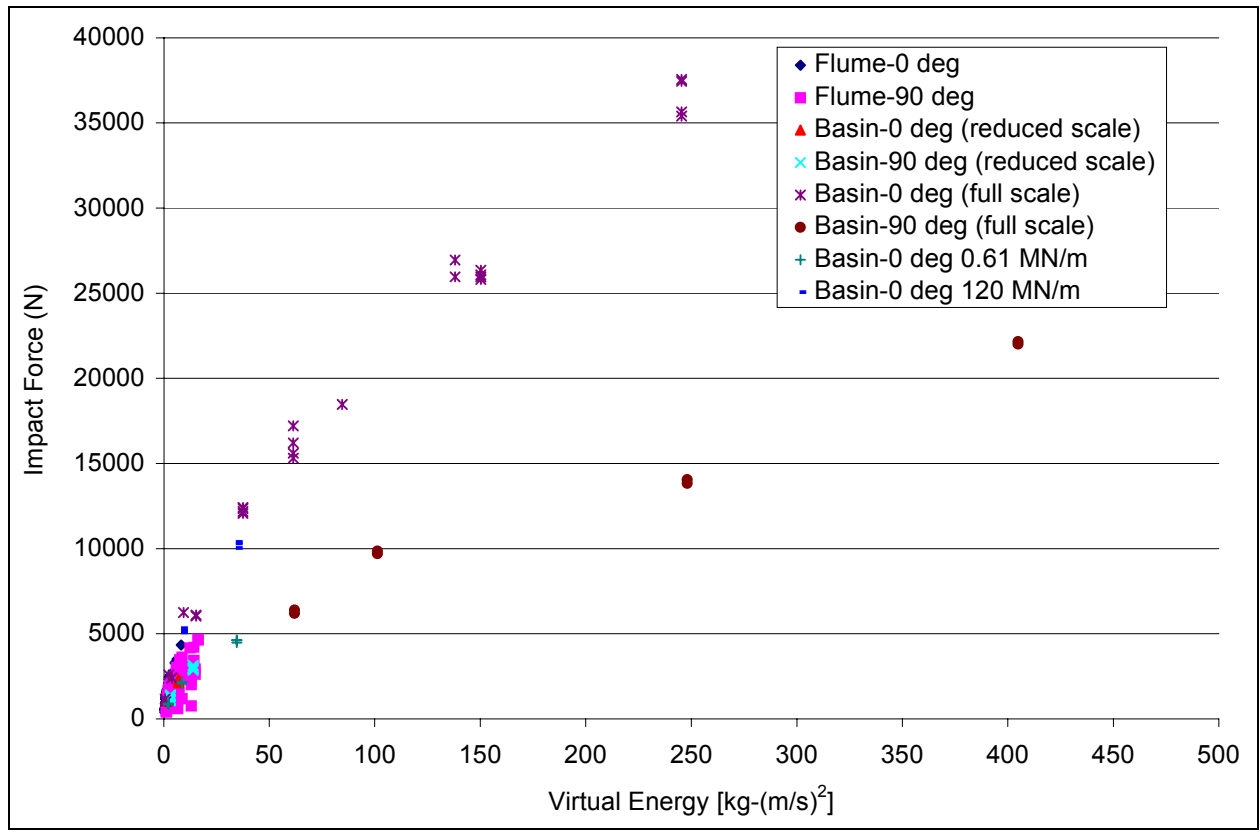

Figure 10. Work-energy approach applied to laboratory data [Test Series 1 (flume), 3 and 4 (basin)]. Added mass is included for $90^{\circ}$ impacts.

find that $S \approx 0.016 \mathrm{~m}$. Note that the line passing through this linear section of Figure $10(K E>50 \mathrm{~J})$ has a y-axis intercept of $8000 \mathrm{~N}$. The maximum impact force is

$$
F_{\mathrm{i}, \max }=125 m u^{2}+8000
$$

where the velocity, $u$, is in $\mathrm{m} / \mathrm{s}$ and the mass, $m$, is in $\mathrm{kg}$. This equation is strictly applicable only for debris with a kinetic energy greater than $50 \mathrm{~J}$. The ability of this approach to predict the maximum impact forces can be seen in Figure 11. This approach consistently overpredicted the impact forces for the reduced-scale logs measured in the flume and test basin. This overprediction resulted from using a constant stopping distance, rather than a stopping distance that is a function of the debris mass and velocity, as indicated in eq 15.

\section{Discussion}

We have applied the three approaches currently used for computing debris and vessel impact forces - contact stiffness (AASHTO 1998), impulsemomentum (FEMA 1995), and work-energy (NAASRA 1990) - to the laboratory data. Each approach estimates the maximum impact force based on the 


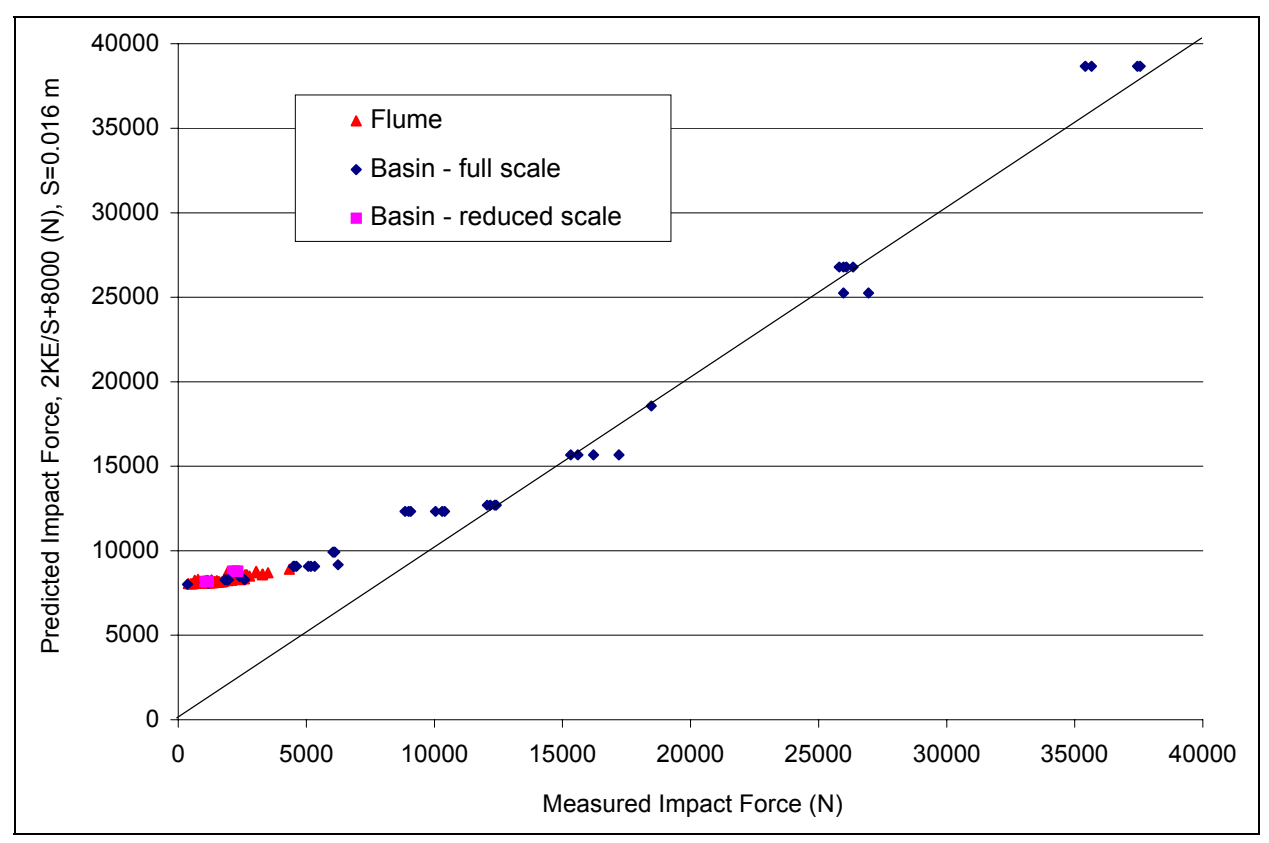

Figure 11. Predicted vs. measured values of impact force using the work-energy approach (eq 19). The data are for $0^{\circ}$ impact orientation.

velocity and mass of impacting woody debris. Each requires an additional parameter: impulse-momentum requires the stopping time; work-energy requires the stopping distance; and contact stiffness requires the effective contact stiffness. Neither impulse-momentum nor work-energy has been critically tested with published data from the laboratory or the field prior to this study. In fact, there seems to be little reason for pursuing either of these approaches, as the required additional parameters - stopping time, in the case of impulsemomentum; stopping distance, in the case of work-energy - are not independent of the debris velocity or mass. As was demonstrated above for a single-degree-offreedom analysis of the collisions, the stopping time is a function of the mass of the debris and the effective contact stiffness, while the stopping distance is a function of the mass of the debris, the effective contact stiffness, and the velocity of the debris. It is clearly incorrect to treat either stopping time or stopping distance as a constant independent of the debris mass or velocity, as these approaches suggest. If these parameters are not treated as constants independent of the debris mass and velocity, but rather the analytical expressions for them are adopted (eq 14 and 15), then there is no advantage to these approaches over that of contact stiffness, as both impulse-momentum and work-energy will be identical to the contact-stiffness approach. 


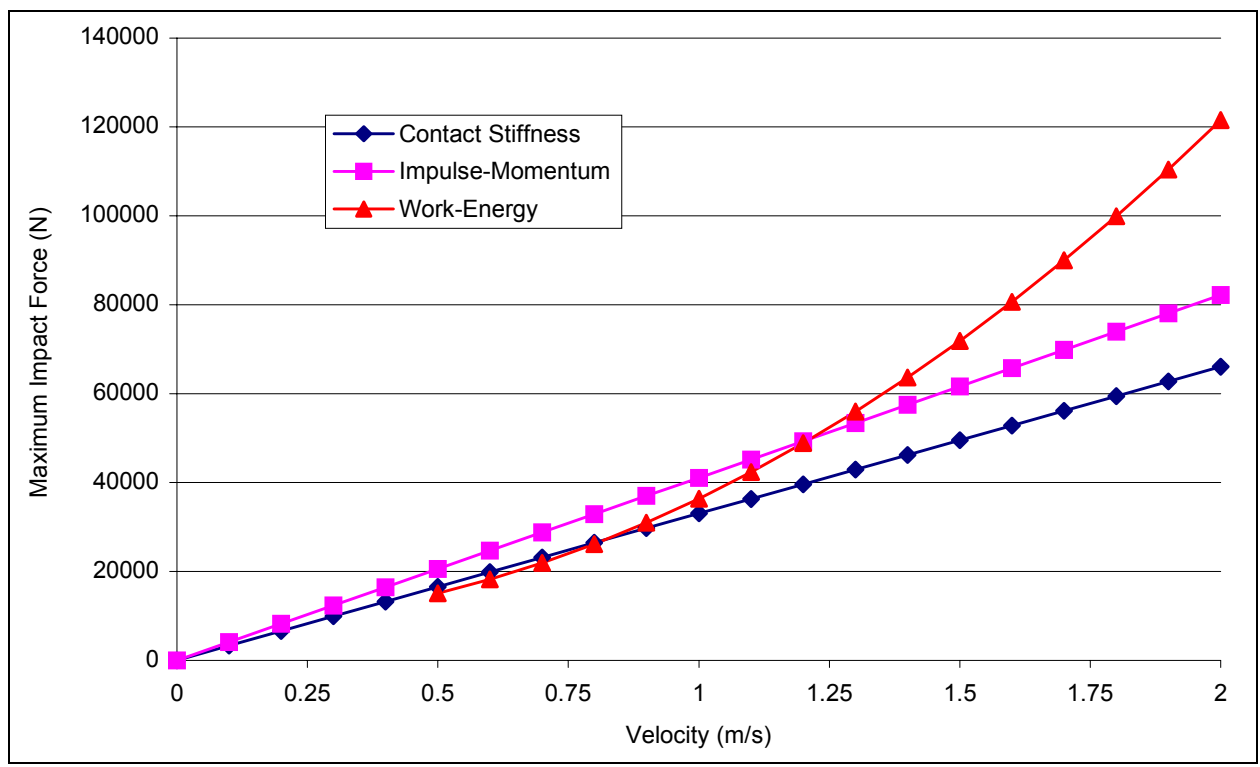

Figure 12. Comparison of the three approaches for estimating the maximum impact force applied to a $455-\mathrm{kg}(1000-\mathrm{lbm}) \mathrm{log}$ at various impact velocities.

The stopping time or stopping distance can be approximated as constants for specified ranges of debris mass, debris velocity, and effective contact stiffness over which their values do not change significantly. We have done this as described above. The result is that neither approach can faithfully reproduce the laboratory results over the entire range of data collected. Of course we could improve the ability of these approaches to reproduce the laboratory results by making the stopping time or stopping distance variable. But then again, if this is done, both approaches will be identical with contact stiffness. We can compare the three approaches by using each (eq 18,19 and 20) to compute the maximum impact force for a 455-kg (1000-lbm) log specified by the FEMA (1995) guidance over a range of impact velocities $(1-2 \mathrm{~m} / \mathrm{s})$. The results are shown in Figure 12. As expected the impulse-momentum approach estimate is greater than the contact-stiffness approach. This is the result of using the stopping time estimated from the laboratory data based on logs with a mass of $200-330 \mathrm{~kg}$ (eq 18). Using this equation will systematically underpredict the maximum impact force for logs with masses less than 200-330 kg-as shown in Figure 9-and systematically overpredict for logs with masses greater than this. In this case the impulsemomentum estimate is about $24 \%$ greater than the contact-stiffness result. We expect that the contact-stiffness approach, fitted over the entire range of laboratory data is the more accurate estimate. 


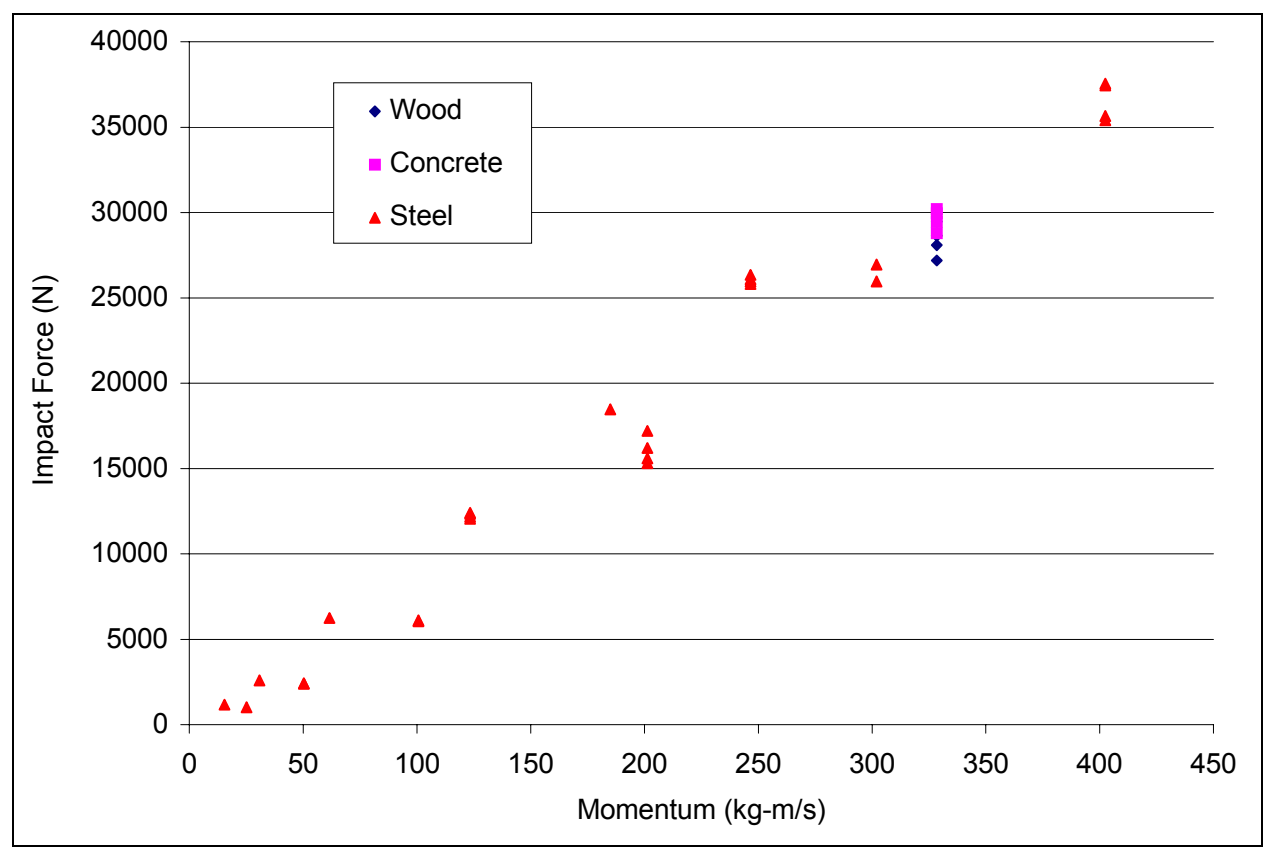

Figure 13. Effects of target material on impact force. The impact orientation is $0^{\circ}$, the impact velocity is $1.2 \mathrm{~m} / \mathrm{s}$, and the structure stiffness is $120 \mathrm{MN} / \mathrm{m}$.

\section{Target Structure Face Material}

Figure 13 shows the effects of target material on impact force. The data for the steel target are taken from all of the basin tests conducted with a $0^{\circ}$ impact. The wooden and concrete targets were measured in Test Series 6. In these tests the overall structure stiffness and impact velocity were held constant, and only the material at the structure contact point (target) was varied. There is relatively little scatter in the maximum impact force when plotted against the momentum of the logs. The construction material of the structure target face appears to have little effect on the maximum impact force. The implication is that the stiffness of the log controls the effective contact stiffness of the collision (eq 2). If the target material were replaced with a material much less stiff than the red pine logs used in the experiments, the force reduction would likely be significant. Concrete and steel are both stiffer than wood, which allows the stiffness of the wood to dictate the resultant maximum impact force. However, in actual structures the overall stiffness of the structure $\left(k_{\mathrm{s}}\right.$, Fig. 1) depends on both the construction material and the structural design (foundation, massiveness, reinforcement, cross bracing, etc.). Thus, in prototype structures the construction material may appear to have a strong influence on impact force - as is suggested in NAASRA (1990) guidance provided in Table 1-when in reality it is the structural stiffness that is responsible for reducing impact forces. 


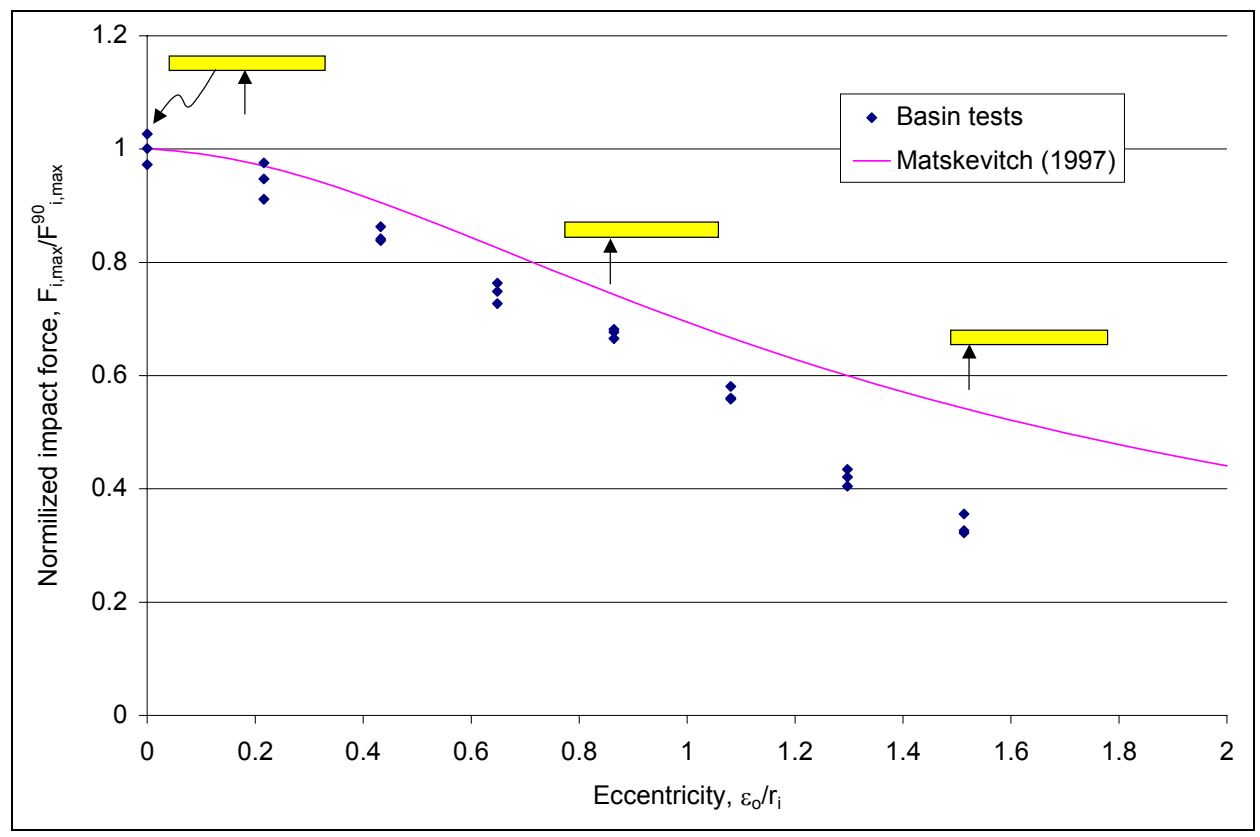

Figure 14. Effects of eccentricity on impact force. The log used was $4.9 \mathrm{~m}$ (16 ft) long and weighed $171 \mathrm{~kg}(378 \mathrm{lbm})$. The diagrams show the impact geometry.

\section{Debris Orientation on Impact}

In all of the tests discussed above, the debris impacted the structure at an angle of $0^{\circ}$ or $90^{\circ}$ to the axis of the logs, and the line of impact passed through the center of gravity of the logs. We collected laboratory data in Test Series 7 and 8 to evaluate the reduction in impact load that could be expected when the impacts were at an oblique angle or eccentric. We investigated each separately. We increased the eccentricity while impacting the structure perpendicular to its long axis (no obliqueness) to evaluate the affect of eccentricity. We increased the obliqueness of the impacts while impacting the structure at its midpoint so that the line of impact passed through the center of gravity of the logs. In general, we found that the maximum impact force decreased in a consistent manner as the eccentricity or obliqueness of the impact increased.

Figures 14 and 15 display the effects of eccentricity and obliqueness, respectively, on the maximum impact force. In these plots the measured maximum impact force has been normalized by $F_{\mathrm{i}, \max }^{90}$, the maximum impact force for a central impact with a log orientation of $90^{\circ}$. For the eccentric impacts in Figure 14 , the impact location is expressed as a normalized distance, where $\varepsilon_{\mathrm{o}}$ is the distance from the center of the $\log$ and $r_{\mathrm{i}}$ is the radius of gyration for the 


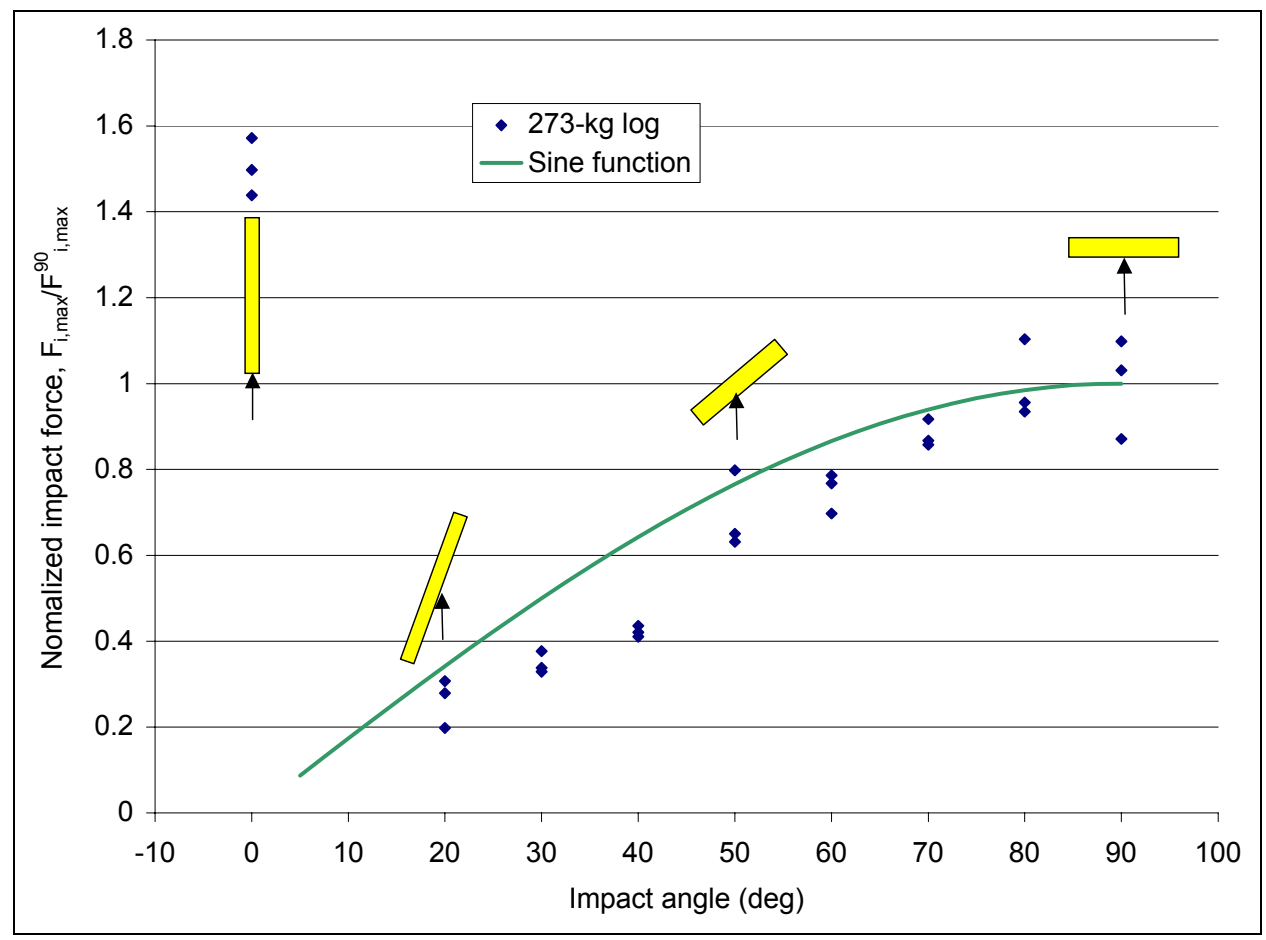

Figure 15. Effects of orientation on impact force. The log used was $8.08 \mathrm{~m} \mathrm{(26.5} \mathrm{ft)}$ long and weighed $93.4 \mathrm{~kg}(206 \mathrm{lbm})$. The diagrams show the impact orientation.

$\log$. We also display the Matskevitch's (1997) estimate of the decrease in the maximum impact force with increasing eccentricity. His estimate provides a reasonable fit to the data, although the measured data show a more rapid decrease in the maximum impact force with eccentricity. We suspect that flexure of the logs, which is not accounted for in Matskevitch's formula, accounts for this discrepancy.

Figure 15 displays the effects of oblique impacts on the maximum impact force. There is a decrease as the impact angle decreases from $90^{\circ}$ to $20^{\circ}$ that correlates well with the sine of the angle, as might be expected $\left(20^{\circ}\right.$ was the smallest angle at which the impact force could be measured for the oblique impacts using our load frame, although impacts occurred at smaller angles). Collisions at angles between $0^{\circ}$ and $20^{\circ}$ directed most of the force toward the edge of the target, putting one or more of the load cells into tension. The force rose abruptly at an impact angle of $0^{\circ}$, as would be expected, as the impact at this orientation was no longer oblique. 


\section{Qualitative Assessment of the Probability of Debris Orientation on Impact}

The above results can be used to estimate the maximum impact force that woody debris may exert on a rigid structure in a floodplain, but they do not address the risk or probability that such an impact will occur. In fact, such an assessment is very site specific and cannot be determined from the laboratory data presented above. In lieu of that, we were interested in conducting a qualitative experiment to explore one aspect of impact debris that we could study in the laboratory: the probability of impact orientation. To generate the statistics that could be used to develop the probabilities, we conducted a test in the flume. In the test a 5.9-kg (13-lbm) log was repeatedly placed in the flow $19 \mathrm{~m}(61 \mathrm{ft})$ upstream and in line with a pile-like structure and released. The log was placed in the center of the flow with an orientation of $0^{\circ}$. The $\log$ was then allowed to flow freely until it impacted the target or reached the end of the flume. We found that of the $200 \operatorname{logs}$ released during this test, 88 missed the load frame entirely. The frequency distribution of the maximum impact force for the 112 logs that struck the target displays an interesting double peak (Fig. 16). Insight into this double peak can be gained from the frequency distribution of the eccentricity of the impacts (Fig. 17) and the frequency distribution of the angle of the impacts (Fig. 18). The peak in the frequency distribution for low eccentricity $(0-0.2)$ results from the fact that low eccentricity can occur with impacts at either $0^{\circ}$ and $90^{\circ}$. Recall also from Figure 13 that relatively high impact loads can occur with impacts angles of $0^{\circ}$ and $90^{\circ}$. The vast majority of the logs hit the

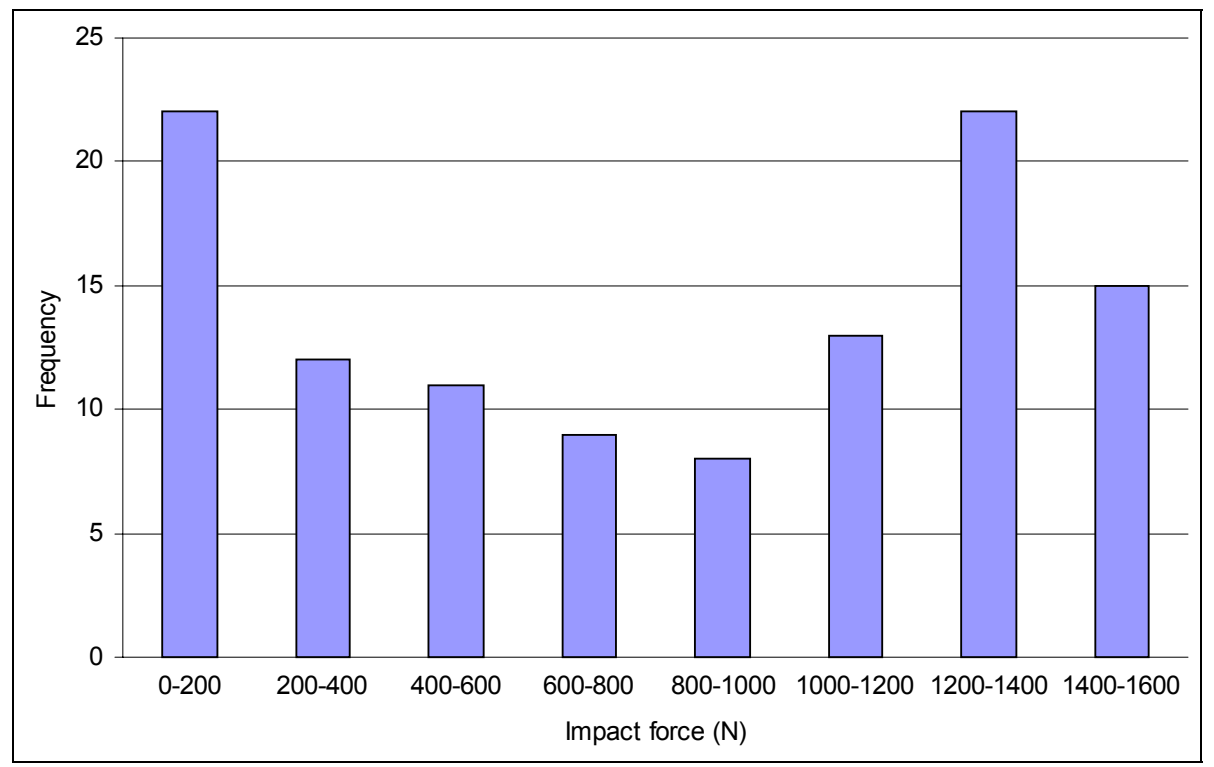

Figure 16. Impact forces measured in the flume using a 5.9-kg (13-lbm) log (Test Series 2 ). These results are only for those samples that struck the target. 
target with an impact angle below $30^{\circ}$, which can best be described as a glancing blow. The net result is the double peak in the frequency distribution of the maximum impact forces, with the first peak at very low impact forces and the second peak at relatively high impact forces.

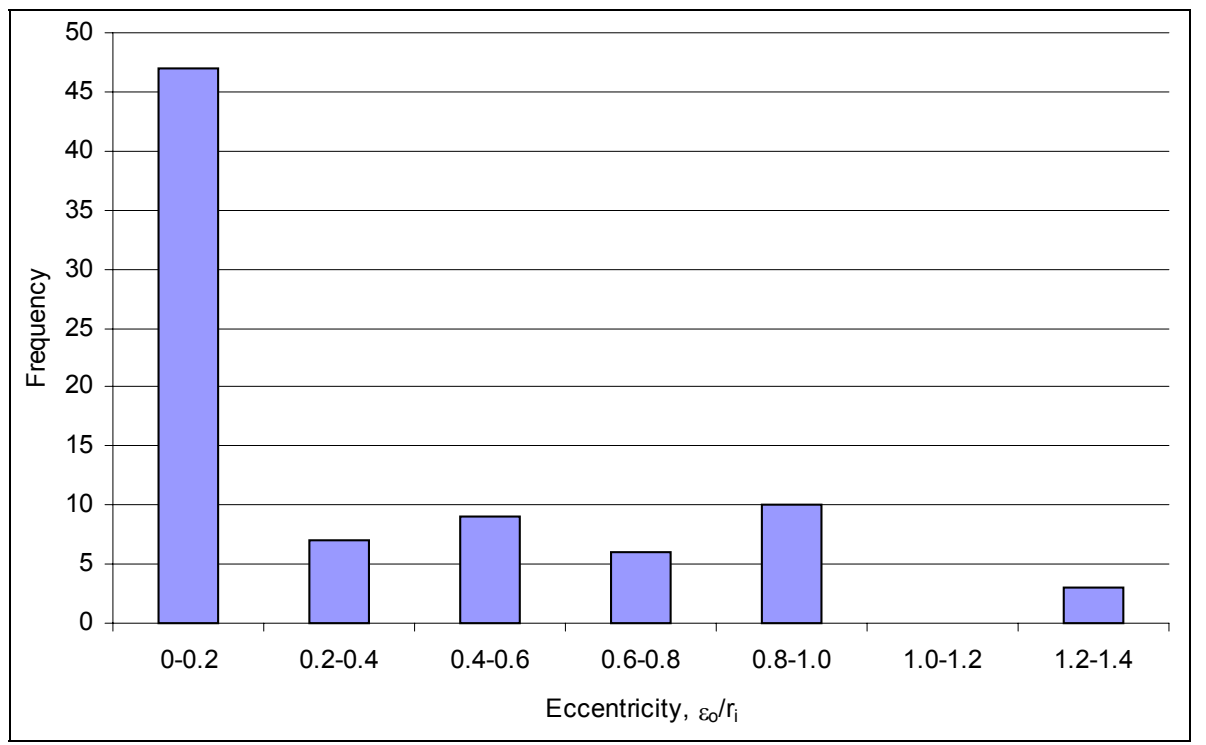

Figure 17. Eccentricity of impact for samples that struck the target (Test Series 2).

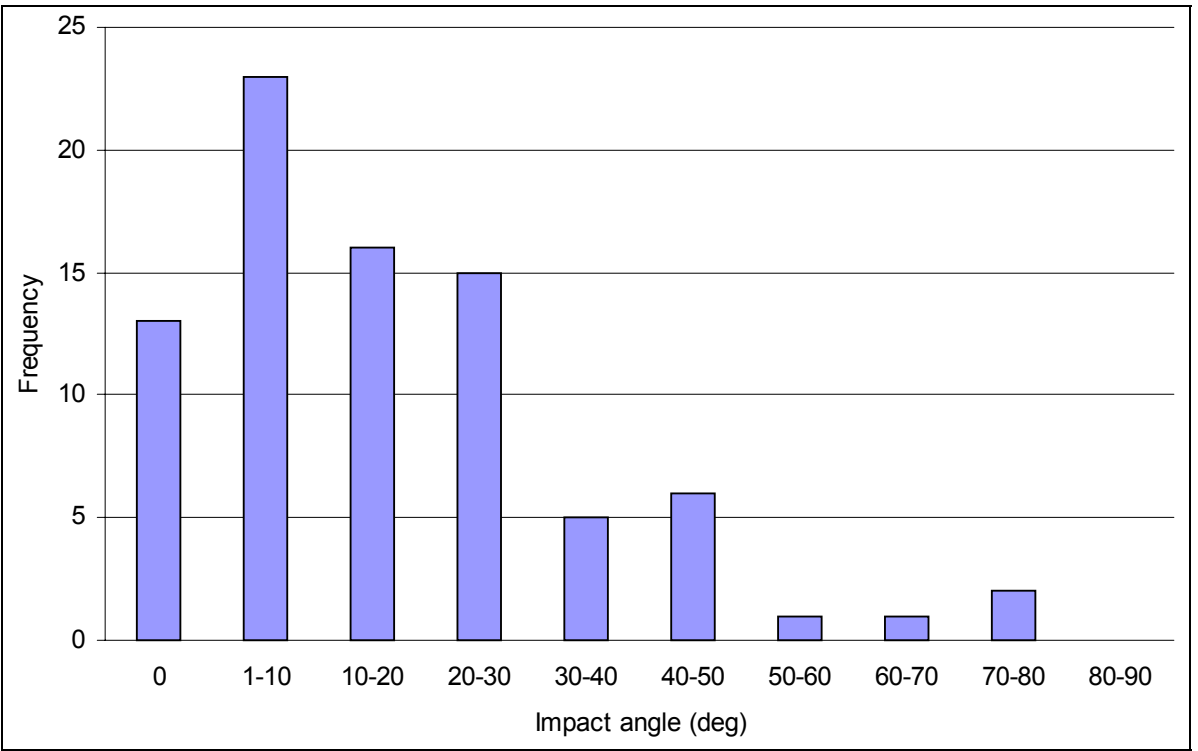

Figure 18. Impact orientation for samples that struck the target (Test Series 2). 


\section{CONCLUSIONS}

We developed a one-degree-of-freedom model to describe impact forces between woody debris and a rigid structure. The maximum impact force is a function of the impact velocity (the relative velocity between the debris and structure), the mass of the debris, and the effective stiffness of the collision between the object and structure. It is independent of the properties of the structure if the structure is considered rigid.

We reviewed the three approaches that represent the existing guidance on design for impact loads: impulse-momentum (FEMA 1995), work-energy (NAASRA 1990), and contact stiffness (AASHTO 1998). Each of these approaches estimates the maximum impact force based on the debris velocity and mass. Each requires that an additional parameter be specified: the stopping time for the impulse-momentum approach; the stopping distance for the work-energy approach; and the effective contact stiffness of the collision for the contactstiffness approach. We show that all three approaches can be derived from a single-degree-of-freedom model of the collision and are equivalent. We show that neither stopping time, in the case of impulse momentum, nor stopping distance, in the case of work energy, is an independent parameter. Stopping time depends on the effective contact stiffness and the debris mass; stopping distance on the effective contact stiffness, the debris mass, and the debris velocity.

Based on the laboratory data, we estimate that the effective contact stiffness of the collision varies over a narrow range; $2.4 \mathrm{MN} / \mathrm{m}$ is a good upper-bound estimate and can be used in the contact-stiffness approach over a wide range of debris mass and velocity. It is problematic to select a single value for stopping time or stopping distance that can be applied over a wide range of debris masses and impact velocities. We could improve the ability of the impulse-momentum and work-energy approaches to reproduce the laboratory results by making the stopping time or stopping distance variable rather than constants. But then both approaches would be identical with the contact-stiffness approach.

Impact geometry has a significant effect on the maximum impact force. Though added mass considerations would suggest that peak forces should occur for a $90^{\circ}$ central impact (broad-side impact), it appears that flexure of the long, slender log upon impact reduces the force significantly. We found that the peak impact force is associated with the log striking the target on its end (with the long axis of the log parallel to the flow direction and normal to the target face). In this orientation the added mass effects are negligible, and the mass of the log can be used directly to compute the impact force. Eccentric and oblique impacts 
systematically reduce the maximum impact force as each is increased. The effects of eccentricity can be estimated using the formula of Matskevitch (1997). The effects of obliqueness are proportional to the sine of the angle of impact.

Regardless of the approach used to estimate the maximum impact force, the data demonstrate that a log striking a rigid structure with its end (with the long axis of the log parallel to the flow direction and normal to the structure face, i.e. $0^{\circ}$ collisions) produces the maximum impact force. In this orientation, added mass is negligible and the mass of the log can be used directly to compute the maximum impact force.

Finally, we qualitatively investigated the probability of the debris orientation on impact by conducting 200 tests in a laboratory flume with flowing water. In each test a log released upstream and in line with a pile-like structure floated freely with the current until impact. More than $40 \%$ of the released logs missed the structure altogether, the majority of the impacts were glancing blows, and fewer than $15 \%$ of the impacts produced a maximum load on the structure. 


\section{LITERATURE CITED}

AASHTO (1998) LRFD Bridge Design Specifications. Second edition. American Association of State Highways and Transportation Officials, p. 26-27.

Baillie, B.R., T.L. Cummins, and M.O. Kimberley (1999) Measuring woody debris in the small streams of New Zealand's pine plantations. New Zealand Journal of Marine and Freshwater Research, 33: 87-97.

D'Aoust, S.G., and R. G. Millar (2000) Stability of ballasted woody debris habitat structures. ASCE Journal of Hydraulic Engineering, 126 (11): 810-817.

FEMA (1995) Engineering principles and practices for retrofitting floodprone residential buildings. FEMA Report No. 259, Federal Emergency Management Agency, January.

Fenske, T.E., C.J. Apelt, and A.C. Parola (1995) Debris forces and impacts on highway bridges. In Proceedings, International Association for Bridge and Structural Engineering, San Francisco, CA, p. 1017-1022.

Harmon, M.E., J.F. Franklin, F.J. Swanson, P. Sollins, S.V. Gregory, J.D. Lattin, N.H. Anderson, S.P. Cline, N.G. Aumen, J.R. Sedell, G.W. Lienkaemper, K. Cromack, Jr., and K.W. Cummins (1986) Ecology of coarse woody debris in temperate ecosystems. In Advances in Ecological Research (A. MacFadyen and E. D. Ford, ed.). New York, NY: Harcourt Brace Jovanovich, 15: $133-302$.

Matskevitch, D.G. (1997) Eccentric impact of an ice feature: Linearized model. Cold Regions Science and Technology, 25: 159-171.

NAASRA (1990) Highway Bridge Design Specification. National Association of Australian State Road Authorities.

Robinson, E.G., and R. L. Beschta (1990) Characteristics of coarse woody debris for several coastal streams of southeast Alaska, USA. Canadian Journal of Fisheries and Aquatic Science, 47: 1684-1693.

Sarpkaya, T., and M. Isaacson (1981) Mechanics of Wave Forces on Offshore Structures. New York: Van Nostrand Rienhold.

U.S. Army Corps of Engineers (1995) Flood-proofing regulations. Engineering Pamphlet 1165-2-314, Washington, DC, December.

Wallace, J.B., and A.C. Benke (1984) Quantification of wood habitat in subtropical coastal plain streams. Canadian Journal of Fisheries and Aquatic Science, 41: 1643-1652. 


\section{APPENDIX A: OVERVIEW OF DEBRIS IN NATURAL WATERBODIES}

Impact loads are the final step in a long chain of events. In this section we describe the process leading to impact in general terms and look specifically at those individual steps of the process that can influence the nature and magnitude of the impact loads. Two alternative sources of debris are described.

\section{Natural Debris}

Floodplain impacts from natural debris arise when coarse woody debris is mobilized and transported to a structure (Fig. A1). Coarse woody debris (CWD) includes snags (standing dead trees), logs, chunks of wood (which result from disintegration of larger snags and logs), large branches, and coarse roots (Harmon et al. 1986). A subset of CWD is large woody debris (LWD): logs and logs with root balls attached. CWD is created through mortality and breakage of living trees. Common agents of mortality are wind, fire, insects, diseases, suppression, and competition. The input rates of CWD in forests range from 0.12 to $30 \mathrm{Mg} \mathrm{ha}^{-1}$ year $^{-1}\left(0.05\right.$ to 13 tons acre year $\left.^{-1}\right)$, with the rate varying primarily with the productivity and massiveness of the trees in the forest. The smallest input rates come from scrub-type stands and the largest from undisturbed, old growth coniferous stands in the Northwest. Once created, CWD finds its way into streams by means of "progressive recruitment processes." These processes include undercutting of streamside trees by gradually migrating streams; windfall of riparian trees; mass movement of soil on hill slopes; transport by floods; soil creep, slumping, and earth flows on hill slopes; and landslides, debris flows, and snow avalanches (D’Aoust and Millar 2000, Harmon et al. 1986).

After CWD has been introduced into streams, a considerable period of time may elapse before the CWD is transported and can potentially cause impacts. During this time the CWD can successively lose twigs, branches, bark, and the rootball and undergo internal decay. Logs entering streams remain intact for periods ranging from a few decades to several hundred years. The distribution of CWD in and along a specific channel reach reflects the balance between the rate of input, decay, and transport away from the reach.

It would be valuable to have an estimate of the mass distribution of discrete pieces of CWD in and along channels to delineate the mass range of potential impactors. General reviews of measurements to characterize CWD in streams can be found in Harmon et al. (1986); see also, for example, Robinson and Beschta (1990), Wallace and Benke (1984), and Baillie et al. (1999). No 


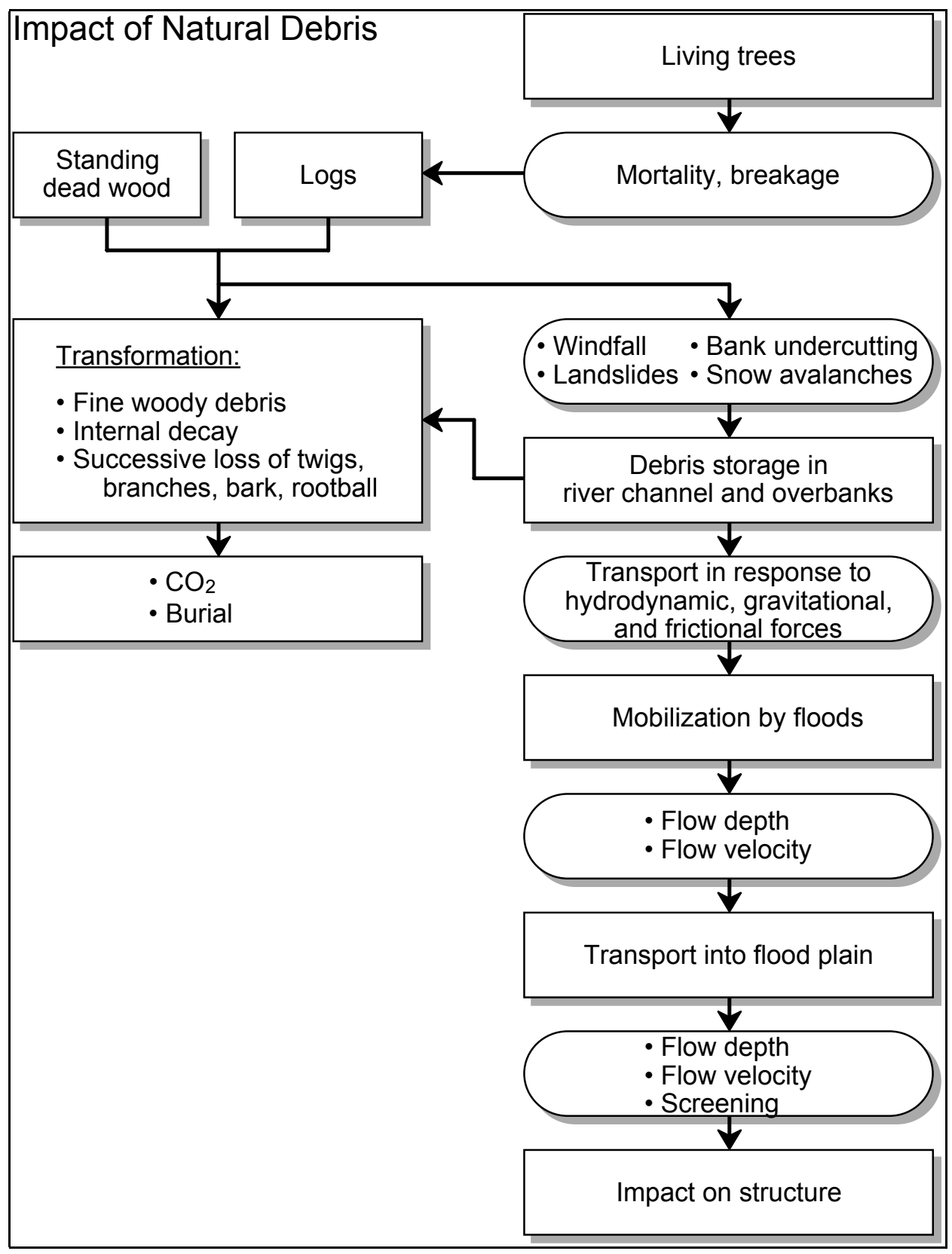

Figure A1. Impact by natural debris.

measurement program has attempted to characterize CWD in streams and channels throughout the U.S. The measurement programs undertaken to date have all focused on specific, well-defined, and small river reaches. Even so, the variability of the measurements is large, reflecting the large variability in the 
creation of CWD between forest types, and the episodic and random nature of the processes that recruit the CWD to the stream channels and transport it away.

D'Aoust and Millar (2000) studied transport of CWD by streams. They investigated the stability of ballasted (anchored by boulders) woody debris, structures used to rehabilitate summer habitat, and critical overwintering refuges. They investigated the balance of forces acting on CWD. The forces were the frictional force of the CWD on the bed and bank resisting transport, and the drag force of the flowing water on the trunk and rootball promoting transport. CWD is transported when the drag force of the flow exceeds the frictional force between the CWD and bed or bank. This frictional force is proportional to the effective weight of the CWD (which is a function of the depth of water) and its density, volume, and geometry. The effective weight is equal to its actual weight when the water is shallow compared to the effective diameter of the CWD. The effective weight decreases as the water level rises and is zero when the CWD fully floats. When floating, the CWD cannot resist any drag and is transported. In addition, the drag force of the flow will increase with the depth of flow. The fluid drag force depends on the orientation of the CWD to the flow. The maximum drag force on the trunk occurs when the trunk of the CWD is perpendicular to the flow or when the rootball is perpendicular to the flow and the trunk is parallel. D'Aoust and Millar assumed that the drag on the trunk could be estimated in the same manner as drag on a cylinder. A drag coefficient of 0.3 was assumed, which corresponds to a turbulent leading edge boundary layer. They estimated the fluid drag on the rootball equivalent to the drag on a disk of equivalent diameter. A drag coefficient of 1.2 was assumed, which is appropriate for circular plates suspended in flow with a Reynolds number of $10^{4}-10^{6}$.

The stability of CWD can be analyzed once the density, volume, and geometry of the CWD and the depth and velocity of the flow are known. As mentioned above, however, the distribution of the characteristics of CWD varies so widely that an analysis is not possible at this time, except for specific examples that have relevance in specific rivers and channels. This short discussion does highlight the importance of flow depth in initiating movement of CWD. It can be expected that CWD will not substantially move except during periods of high water and floods.

We can define three possible ranges of flow depth to describe transport of CWD: shallow, intermediate, and full. If the flow depth is less than the depth required to float the CWD, the depth can be considered to be shallow. In this range of depth the fluid drag forces are not sufficient to overcome the frictional forces between the CWD and the bed. The CWD cannot be transported in areas where the depth is shallow. In the intermediate range the CWD will be substan- 
tially floating but portions of the rootball or branches may be in continual contact with the bed. The continual contact will develop frictional forces with the bed that will reduce the transport velocity of the CWD in comparison to the flow velocity. At full depth the CWD will not be in any substantial contact with the bed and will be transported at the flow velocity.

Once the conditions for transport are met, the CWD can be potentially transported in all areas where the flow depth is in the intermediate range or greater except if that area is protected in some manner such as by screens of trees, fences, or barriers. The effectiveness of any barrier to prevent the passage of CWD depends on the relative geometry of the barrier and the CWD. It is expected that CWD will be transported with the long dimension of its trunk parallel to the flow. Important ratios will be the relative size of the opening in the barrier and the effective diameter of the CWD, and the relative size of the opening in the barrier and the effective diameter of the rootball of the CWD. If the spacing between barriers is less than or equal to either diameter, the barrier will be effective in keeping CWD from passing through. Barriers may also be effective if they produce a bend in the fluid flows with a radius of curvature that is less than or equal to the length of the trunk of the CWD.

\section{Non-Natural Debris}

Floodplain impacts from non-natural debris arise when man-made objects or debris resulting from the destruction of structures in the floodplain are mobilized and transported to a structure (Fig. A2). Man-made objects in the floodplain are either created and/or used there or are carted to the floodplain and abandoned. Only objects that will float can cause impacts. These are all types of wooden objects, such as poles, fencing, and lumber, as well as tanks, floats, airtight containers, etc., that can generate sufficient buoyancy to overcome their weight. Tanks filled with air or with material less dense than water, such as hydrocarbons, are possible sources of debris. The variety of possible objects is so vast that no categorization is possible. 


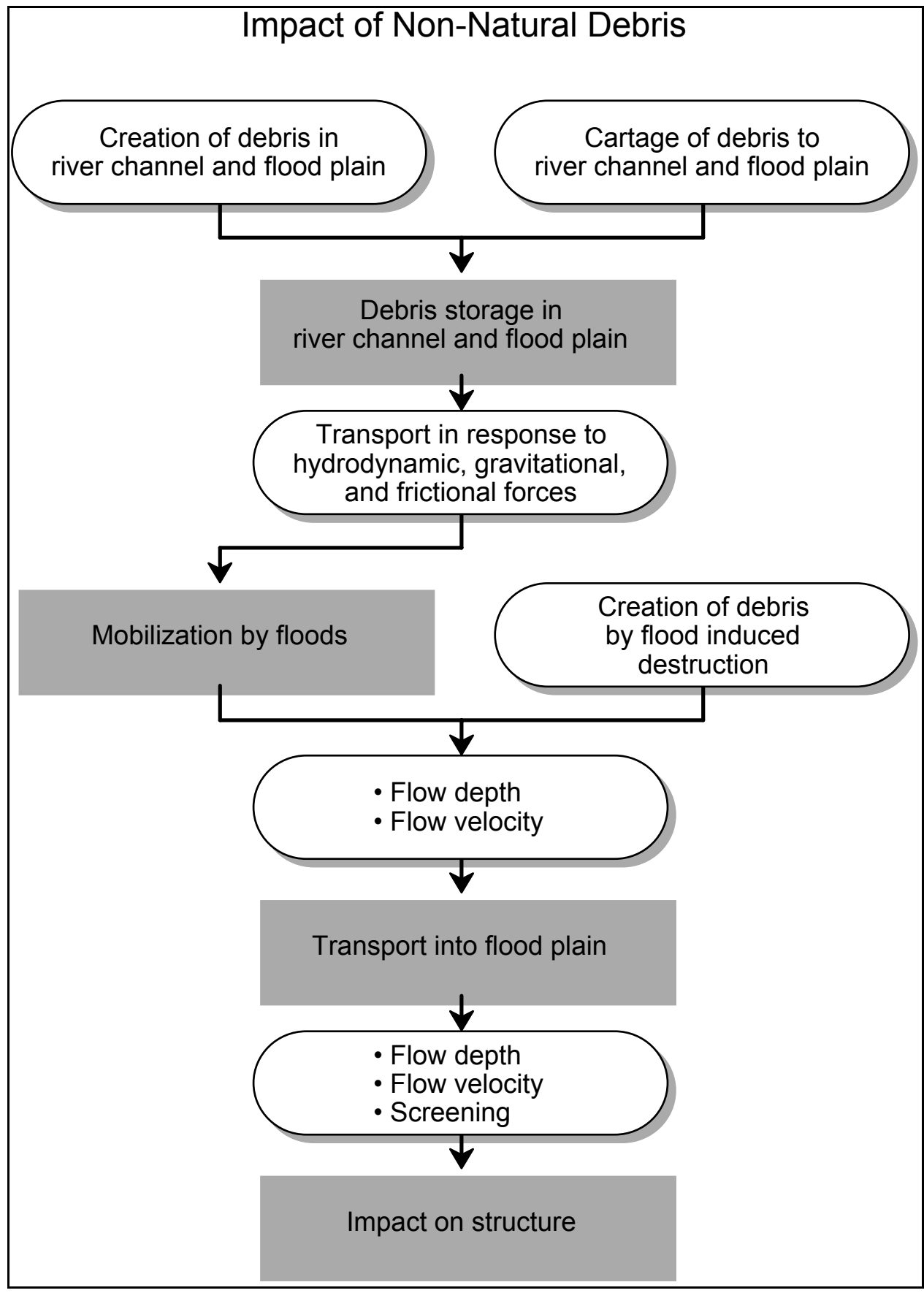

Figure A2. Impact by non-natural or man-made debris. 


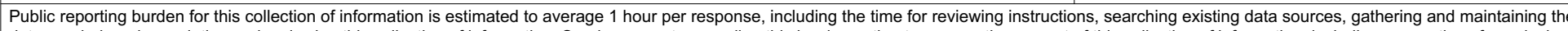

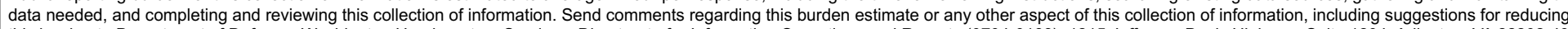

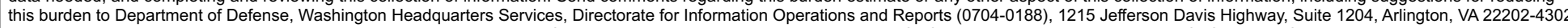

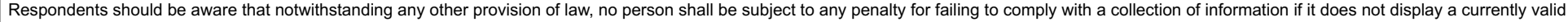
OMB control number. PLEASE DO NOT RETURN YOUR FORM TO THE ABOVE ADDRESS.
1. REPORT DATE (DD-MM-YY)
2. REPORT TYPE
February 2002
Technical Report
3. DATES COVERED (From - To)

4. TITLE AND SUBTITLE

5a. CONTRACT NUMBER

Maximum Impact Force of Woody Debris on

5b. GRANT NUMBER

Floodplain Structure

c. PROGRAM ELEMENT NUMBER

\section{AUTHOR(S)}

Robert B. Haehnel and Steven F. Daly

5d. PROJECT NUMBER

5e. TASK NUMBER

5f. WORK UNIT NUMBER

7. PERFORMING ORGANIZATION NAME(S) AND ADDRESS(ES)

8. PERFORMING ORGANIZATION REPORT NUMBER

U.S. Army Engineer Research and Development Center

Cold Regions Research and Engineering Laboratory

72 Lyme Road

Hanover, New Hampshire 03755-1290

ERDC/CRREL TR-02-2

9. SPONSORING/MONITORING AGENCY NAME(S) AND ADDRESS(ES)

10. SPONSOR / MONITOR'S ACRONYM(S)

Federal Emergency Management Agency

11. SPONSOR / MONITOR'S REPORT NUMBER(S)

\section{DISTRIBUTION / AVAILABILITY STATEMENT}

Approved for public release; distribution is unlimited.

Available from NTIS, Springfield, Virginia 22161.

13. SUPPLEMENTARY NOTES

\section{ABSTRACT}

We collided woody debris (i.e. logs) with structures using flume and test basin laboratory facilities to investigate the maximum impact force that floodplain structures are exposed to by floating woody debris. The tests investigated the influence of collision geometry and construction material of the structure face on the maximum impact forces. Collision geometry was determined by the debris orientation on impact. We reviewed the three approaches that represent the existing guidance on maximum impact forces. Each approach estimates the maximum impact force based on the debris velocity and mass. We show that all the existing approaches can be derived from a singledegree-of-freedom model of the collision and can be considered to be equivalent. The laboratory data show that the maximum impact force was associated with a log striking a rigid structure with its end. Oblique and eccentric collisions reduced the maximum impact load in a predictable and consistent manner. The approach we refer to as "contact stiffness," a linear, one-degree-of-freedom model with no damping, was able to reproduce the laboratory results over the entire range of data, with an effective contact stiffness of $2.4 \mathrm{MN} / \mathrm{m}$. All the existing guidance was applied to the laboratory data, and the strengths and weakness of each are discussed.

15. SUBJECT TERMS

Floating debris Impact forces

Floodplain structures Woody debris

\begin{tabular}{|c|c|c|c|c|c|}
\hline \multicolumn{3}{|c|}{ 16. SECURITY CLASSIFICATION OF: } & \multirow{2}{*}{$\begin{array}{l}\text { 17. LIMITATION OF } \\
\text { OF ABSTRACT }\end{array}$} & \multirow{2}{*}{$\begin{array}{l}\text { 18. NUMBER } \\
\text { OF PAGES }\end{array}$} & \multirow{2}{*}{\begin{tabular}{|l|} 
19a. NAME OF RESPONSIBLE PERSON \\
19b. TELEPHONE NUMBER (include area code)
\end{tabular}} \\
\hline a. REPORT & b. ABSTRACT & c. THIS PAGE & & & \\
\hline $\mathrm{U}$ & $\mathrm{U}$ & $\mathrm{U}$ & $\mathrm{U}$ & 52 & \\
\hline
\end{tabular}




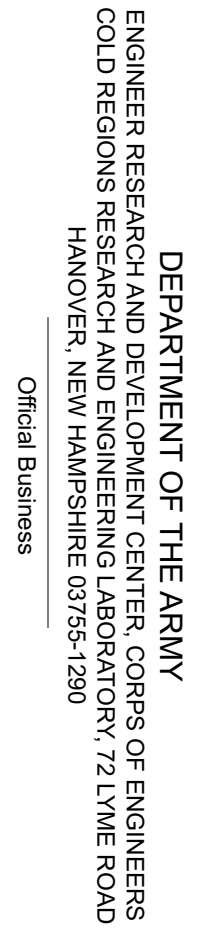

